\title{
Estrategias de inversión exterior que limitan la exposición al riesgo: el papel de las adquisiciones parciales*
}

\author{
Cristina López Duarte \\ Dpto. de Administración de Empresas (Universidad de Oviedo) \\ Marta M. ${ }^{a}$ Vidal Suárez \\ Dpto. de Administración de Empresas (Universidad de Oviedo)
}

\section{Resumen}

En este trabajo se analiza la utilización de adquisiciones parciales (APs) como fórmula de inversión directa en el exterior (IDE), identificando los rasgos distintivos que las convierten en un modo de entrada diferenciado respecto de otras fórmulas inversión. Utilizando como fuente de evidencia empírica una base de datos, creada al efecto, que compila las adquisiciones parciales realizadas por las empresas españolas admitidas a cotización oficial en la Bolsa de Madrid en el período 1988-2003, se identifica un perfil diferenciado para las diferentes categorías de adquisición parcial identificadas.

Palabras clave: adquisición parcial, toehold, inversión directa en el exterior, crecimiento internacional.

Clasificación JEL: F21, F23, M16.

\begin{abstract}
Abastract
Foreign direct investments (FDIs) can be carried out through different entry modes, among others, partial acquisitions (PAs). This particular entry mode and its differentiated features are analyzed in this paper. An empirical test is carried out based on a database of FDIs (1988-2003) made by listed Spanish firms whose shares are traded on the Madrid Stock Exchange. A typology of PAs is identified as well as a profile for each identified category.

Keywords: partial acquisition, toehold, foreign direct investment, international growth.

JEL classification: F21, F23, M16.

\section{Introducción}

En el marco de la Gestión Internacional resulta prolija la literatura que aborda la elección del modo de implantación en el mercado receptor asociado a la realización de inversiones directas en el exterior (IDEs), resultando múltiples las perspectivas o marcos teóricos desde las que se ha abordado el tema ${ }^{1}$.

\footnotetext{
* Los autores agradecen el apoyo financiero proporcionado por la Universidad de Oviedo (Proyecto de investigación: UNOV 08-MAR-102).

${ }^{1}$ Una exhaustiva revisión de la literatura al respecto se puede encontrar, al menos en parte, en BROTHERS y HENNART (2007)
} 
En el presente trabajo se aborda la elección del modo de entrada desde la perspectiva de las denominadas foothold entry strategies (Meyer y Tran, 2006); es decir, las estrategias de inversión exterior que permiten a la empresa inversora tomar un primer contacto con el mercado receptor sin la necesidad de incurrir en un excesivo compromiso de recursos en el mismo. Tales estrategias son susceptibles de materializarse a través de dos fórmulas concretas: (I) la creación de una empresa conjunta en el mercado receptor; es decir, la creación de una nueva empresa cuya propiedad y control es compartido con (al menos) un socio con el que la empresa inversora coopera, transfiriendo ambos una parte de sus recursos a la nueva entidad y (II) la realización de una adquisición parcial (AP) o empresa conjunta por adquisición; es decir, la adquisición de una parte del capital de una empresa ya localizada en el mercado objetivo.

La implantación en un mercado extranjero a través de una foothold entry strategy proporciona a la empresa cierta flexibilidad o capacidad de reacción ante potenciales cambios del entorno que puede constituir una fuente de ventaja competitiva para la empresa inversora particularmente relevante en entornos inestables. Así, en términos de Kogut (1991) y Kogut y Kulatilaka (1994), la creación de una empresa conjunta constituye una plataforma desde la que la empresa puede materializar posteriores inversiones. Adicionalmente, la implicación únicamente parcial de la empresa inversora en el proyecto, facilita la revocación de su decisión inversora en caso de que el mismo evolucione de forma no favorable. De igual forma, la realización de una adquisición parcial también puede constituir un primer paso en el proyecto de inversión exterior de una empresa. Tal y como apuntan López-Duarte y García-Canal (2002), la materialización de una IDE a través de una adquisición parcial evita al inversor extranjero la necesidad de pagar íntegramente por los activos y recursos de la empresa objetivo -caso de las adquisiciones totales-; antes al contrario, la adquisición de una parte del capital de la empresa objetivo constituye un primer paso que permite a la empresa inversora protegerse de la asimetría de información existente en todo proceso de adquisición: su posición en el capital de la empresa objetivo proporciona a la empresa inversora la capacidad para acceder a información sobre aquélla no accesible desde el exterior. Tal información le proporciona, a su vez, una posición privilegiada para determinar el valor real de la empresa objetivo y, en su caso, renegociar las condiciones en las que está dispuesta a aumentar su posición en el capital de la misma. Los estudios que analizan la creación de empresas conjuntas como métodos de implantación internacional son particularmente abundantes; por el contrario, la realización de adquisiciones parciales constituye una fórmula de implantación internacional que apenas ha recibido atención en la literatura ${ }^{2}$, constituyendo lo que Jakobsen y Meyer (2007) denominan el modo de entrada ignorado.

\footnotetext{
${ }^{2}$ Entre los escasos trabajos que abordan las adquisiciones parciales como fórmula de implantación internacional se encuentran los de BARKEMA y VERMEULEN (1998), LÓPEZ-DUARTE y GARCÍA-CANAL (2002), CHEN y HENNART (2004), MEYER y ESTRIN (2006), MEYER y TRAN (2006) y JAKOBSEN y MEYER (2007).
} 
El objetivo del presente trabajo consiste en realizar un análisis de las adquisiciones parciales como modo de implantación internacional, identificando sus rasgos distintivos y las implicaciones que para la empresa inversora se derivan de los mismos. A continuación, se lleva a cabo un estudio empírico, de carácter exploratorio, cuyo principal objetivo radica en identificar las pautas de utilización de diferentes tipos de adquisiciones parciales como fórmula de implantación internacional por parte de las empresas españolas. El trabajo se cierra presentando las principales conclusiones.

\section{Las adquisiciones parciales como modo de implantación internacional: rasgos distintivos}

Según se ha mencionado, la realización de una adquisición parcial constituye una fórmula de materializar las inversiones directas en el exterior diferenciada respecto de otras alternativas más frecuentemente estudiadas en la literatura sobre modos de implantación internacional. El que la literatura apenas haya prestado atención individualizada a dicha fórmula se debe al hecho de que la misma comparte con otras alternativas -en concreto, con las adquisiciones totales y las empresas conjuntasalgunos rasgos, lo que ha llevado a numerosos autores a englobarlas conjuntamente con unas u otras en los estudios realizados.

Así, al igual que ocurre en el caso de las adquisiciones totales, la realización de una adquisición parcial como fórmula de materializar una inversión directa en el exterior radica en la toma de control por parte de un inversor extranjero del capital de una empresa localizada en el mercado receptor. Desarrollar dicho mercado a partir de una empresa ya localizada en el mismo permite acelerar el proceso de implantación de la empresa inversora -al acceder a las infraestructuras y cuota de mercado de la empresa adquirida-e, incluso, mantener la imagen de empresa local frente a extranjera (caso, por ejemplo, de mantener el nombre y la marca de la empresa adquirida). El matiz diferenciador entre ambas fórmulas radica en que en el caso de una adquisición parcial el inversor extranjero únicamente adquiere una parte de tal capital (Sudarsanan, 1995), participación que le proporciona cierto grado de control y capacidad de influencia sobre la gestión de la empresa adquirida (Spencer et al., 1998). La toma de una participación parcial favorece el desarrollo del denominado efecto hostage (Chen y Hennart, 2004), el cual favorece la reducción de la asimetría de información (y los costes que para la empresa compradora se derivan de la misma), así como los costes de integración ex post inherentes a un proceso de adquisición total.

De otro lado, entre los principales rasgos compartidos por empresas conjuntas y adquisiciones parciales se encuentran el hecho de constituir fórmulas de implantación no agresivas que implican una reducida exposición al riesgo de la empresa inversora, así como la necesida0d de compartir con otra/s empresa/s la propiedad, el control y el derecho a participar en los beneficios de la empresa localizada en el 
mercado receptor. La adquisición de una parte del capital de una empresa ya implantada en el mercado receptor, frente a la creación de una nueva entidad en el mismo, constituye el principal factor diferenciador entre ambas fórmulas. Así, la constitución de una empresa conjunta implica la transferencia por parte de los socios implicados de una parte de sus recursos a la nueva empresa. En concreto, cada uno de los socios aporta a la nueva entidad únicamente aquellos recursos que son precisos para el desarrollo de la actividad de la misma. Por el contrario, cuando una inversión se materializa a través de una adquisición parcial, la empresa inversora adquiere un porcentaje de todos los recursos de la empresa adquirida, no únicamente de aquellos que considera particularmente valiosos o necesarios para desarrollar su actividad en el mercado receptor (Barkema y Vermeulen, 1998; López Duarte y García Canal, 2002).

Un último rasgo que las adquisiciones parciales comparten con las dos fórmulas de inversión ya apuntadas, radica en el hecho de que, en el caso de procesos de internacionalización las tres fórmulas permiten a la empresa extranjera acceder a recursos específicos del mercado receptor que generalmente están en manos de empresas locales y no son susceptibles de ser adquiridos a través del mercado, tal y como apuntan, entre otros, Kogut y Singh (1988), Hennart y Reddy $(1997,2000)$ y Reuer y Koza (2000).

Atendiendo a lo recogido en los párrafos anteriores, cabe concluir que dos son los rasgos distintivos de las adquisiciones parciales como fórmula de inversión exterior: (I) la necesidad de compartir la gestión, el riesgo y la apropiación de beneficios con otro/s socio/s y (II) el hecho de desarrollar el mercado receptor a partir de una empresa previamente localizada en el mercado recpetor. Tal y como apuntan diversos autores -López-Duarte y García-Canal (2002); Chen y Hennart (2004); Jakobsen y Meyer (2007)-, esta combinación de rasgos las convierte en un modo de entrada híbrido entre empresas conjuntas y adquisiciones totales, pero diferenciado respecto de ambos. Si bien ambos aspectos son comunes a todas las adquisiciones parciales, rasgos tales como el porcentaje de capital de la empresa objetivo adquirido por la inversora, el número de empresas adquirentes que se implican en un mismo proceso, las características de el/los vendedores o los objetivos perseguidos por la empresa inversora respecto a la estabilidad de porcentaje adquirido permiten identificar un amplio abanico de fórmulas diferenciadas. Si bien estos rasgos caracterizadores de una adquisición parcial aparecen considerados en los trabajos de López Duarte y García-Canal (2002), Meyer y Tran (2006) y Jacobsen y Meyer (2007); ninguno de éstos desarrolla un análisis conjunto de los mismos; antes al contrario, cada uno de estos estudios profundiza en la consideración aislada de alguno de los aspectos mencionados -número de empresas implicadas, tipo de vendedor o porcentaje de capital adquirido, respectivamente. Tomando como base tales estudios, se ha procedido a identificar una tipología de adquisiciones parciales que se recoge en los siguientes párrafos y se sintetiza en el Cuadro 1. 


\section{Clasificación de las adquisiciones parciales}

\subsection{El número de empresas implicadas en el proceso}

Tradicionalmente, la implantación en un mercado extranjero vía adquisición se ha analizado desde la perspectiva de una única empresa inversora. Existen, no obstante, procesos en los que son varias empresas las que conjuntamente realizan la adquisición de una empresa local realizando lo que se ha denominado en la literatura una «adquisición compartida» (López-Duarte y García-Canal, 2002) o empresa conjunta previa a la adquisición (Jakobsen y Meyer, 2007). Así, en una adquisición tradicional, sea ésta total o parcial, se ven implicadas únicamente dos empresas: la adquirente y la objetivo o adquirida. Por el contrario, en un proceso de adquisición compartida varias empresas toman conjuntamente una participación en el capital de una tercera empresa localizada en el mercado objetivo, pudiendo resultar dicha participación conjunta total -el grupo de adquirentes se hace con el 100\% del capital de la empresa objetivo- o parcial -dicho grupo adquiere conjuntamente únicamente una parte del capital de la empresa objetivo. La realización de una adquisición compartida requiere, por tanto, la realización de dos procesos consecutivos de diferente naturaleza: en primer lugar, debe desarrollarse un acuerdo de cooperación entre las diferentes empresas adquirentes en el que se pactan las condiciones en las que se llevará a cabo la adquisición y, en segundo lugar, se materializa la adquisición propiamente dicha de la empresa objetivo. Dicho acuerdo de cooperación suele materializarse en la creación de una empresa conjunta participada por las diferentes adquirentes, siendo dicha entidad compartida la que posteriormente realiza la adquisición.

Tal y como apuntan López-Duarte y García-Canal (2002) y Jakobsen y Meyer (2007), esta fórmula de adquisición compartida resulta muy utilizada en los procesos de adquisición de empresas que son privatizadas, al objeto de dar cabida a socios locales cuya participación en el proceso constituye con frecuencia un requisito explícitamente recogido en el pliego de condiciones de la privatización y/o cuya participación es requerida por los restantes inversores al objeto de que aporten contacto y conocimientos sobre el mercado receptor.

\subsection{El volumen y la estabilidad del capital adquirido}

El porcentaje de capital de la empresa objetivo adquirido por la inversora constituye una variable básica en un proceso de adquisición parcial. En principio, cualquier adquisición que implique una participación superior al 0 e inferior al 100\% del capital de la empresa objetivo constituye una adquisición parcial (Lindqvist, 2004a; 2004b). La clasificación de los procesos de adquisición trasciende, no obstante, la sencillez de tal definición. De un lado, en el marco de la literatura sobre expansión internacional, las tomas de capital que afectan a un volumen inferior al 10\% de capi- 
tal de la empresa objetivo se consideran inversiones de cartera o de naturaleza meramente financieras, no siendo identificadas, por tanto, como inversiones directas en el exterior ${ }^{3}$. Estas tomas de participación minoritarias únicamente traspasan la frontera existente entre inversiones de cartera e inversiones directas cuando constituyen un toehold; es decir, un primer paso en un proyecto inversor de superior envergadura. Del otro, parece existir un amplio consenso en la literatura al respecto en calificar como adquisiciones totales aquellas en las que el volumen de capital adquirido por la empresa inversora alcanza y/o traspasa la frontera del 95\% del capital de la empresa objetivo ${ }^{4}$.

En relación al amplio abanico de posibilidades comprendido entre los límites antes mencionado no existe un consenso respecto a su clasificación, si bien la mayor parte de los estudios parecen basarse en alguno de los dos siguientes criterios: el derecho que obtiene la empresa inversora a participar en los beneficios obtenidos por la empresa (parcialmente) adquirida y el grado de control sobre la gestión de aquélla obtenido por la empresa inversora a través de su participación. Atendiendo al primer criterio, el porcentaje de capital adquirido constituye una buena aproximación del derecho de la empresa inversora a participar en los beneficios generados por la sociedad participada, En este sentido, cabe distinguir entre participaciones mayoritarias (superiores al 50\% del capital) y minoritarias (inferiores a dicho umbral, si bien superiores al $10 \%$ apuntado anteriormente). La literatura al respecto apunta al hecho de que las primeras tienden a presentar características más similares a las de las adquisiciones totales que las segundas (Lindqvist, 2004a; 2004b). La utilización de este criterio de clasificación presenta como ventaja añadida la relativa sencillez relativa a la obtención de la información al respecto. La clasificación de las APs atendiendo a los derechos de control sobre la gestión de la empresa adquirida resulta más compleja ya que los mismos dependen no sólo del porcentaje de capital adquirido, sino también de cómo se distribuye el resto del capital no adquirido, así como de la existencia de reglas de mayorías cualificadas o títulos de propiedad con diferentes derechos. En este sentido, algunos autores (fundamentalmente en el marco de la literatura dirigida a analizar la creación de empresas conjuntas ${ }^{5}$ ) distinguen entre participaciones dominantes -la empresa inversora consigue el control efectivo de la empresa local, al margen del porcentaje de capital que tome en el proceso-, frente a participaciones no dominantes.

Junto a los derechos de control y la participación en beneficios, coexiste, no obstante, un tercer factor susceptible de condicionar de forma importante las características de una AP: el grado de estabilidad de la participación tomada o, en otras palabras, el interés de de la empresa inversora en mantener o modificar dicha participación a lo largo del tiempo. Tal y como apuntan Meyer y Estrin (2006), la consideración de tal grado de estabildiad permite diferenciar entre adquisiciones puntua-

\footnotetext{
${ }^{3}$ Véase OCDE (1996) y la legislación española al respecto.

4 Véanse, a título de ejemplo, GOMES-CASERES (1989) y HENNART y REDDY (1997).

5 Véase, por ejemplo, KILLING (1983), BEAMISH (1988) y BLODGETT (1992).
} 
les -la empresa inversora adquiere, y mantiene a lo largo del tiempo, un determinado porcentaje de capital de la empresa objetivo- y adquisiciones escalonadas o en etapas -la empresa inversora cambia gradualmente su participación en el capital de la empresa objetivo, de tal forma que la adquisición de una participación parcial constituye únicamente el comienzo de un proceso cuyo objetivo final es lograr la totalidad (o la mayoría) de la propiedad y el control de la empresa objetivo.

La realización de un toehold; es decir, la adquisición de una primera participación minoritaria en la empresa objetivo, realizada a través del mercado y previa al anuncio público por parte de la empresa inversora de su interés en tomar el control de la empresa objetivo constituye un fenómeno ampliamente analizado en el ámbito financiero ${ }^{6}$; no así en el campo de la Gestión Internacional. Las principales ventajas que para la empresa inversora supone la realización de una inversión de esta naturaleza pueden resumirse en los siguientes términos: (I) la adquisición de tal participación minoritaria a través del mercado permite a la empresa adquirente hacerse con un porcentaje de los títulos de propiedad de la empresa adquirida a un precio inferior al precio al que se materialice la oferta de adquisición -el denominado toehold premium que recoge la variación en el precio de las acciones de la empresa objetivo antes y después de que el anuncio de la adquisición se haga público- y (II) la posesión de un toehold proporciona a la empresa un mayor poder de negociación frente a potenciales rivales que también deseen hacerse con el control de la empresa objetivo, pero carezcan de tal participación, llegando a impedir, incluso, la realización de ofertas rivales por aquélla. Entre los efectos negativos de la toma de tal participación minoritaria se encontrarían: (I) la potencial revelación al mercado por parte de la empresa adquirente de información privada relativa a la valoración que realiza de la empresa objetivo, (II) el incremento en el precio de mercado de los títulos de propiedad de esta última (hecho que redunda en un encarecimiento de la adquisición final) -la escalada en el precio de lo títulos suele ser mayor cuando el mercado anticipa batallas por el control de la empresa objetivo- y (III) la potencial reacción hostil del equipo gestor de la empresa objetivo en caso de detectar la toma de participación ${ }^{7}$.

La adquisición de un toehold puede ser considerada como una inversión directa, frente a una inversión de cartera, en tanto que forma parte de un proceso de toma de control sobre la empresa objetivo. En este caso, la participación minoritaria constituye una situación meramente temporal dirigida a evolucionar hacia una fórmula de propiedad que garantice a la empresa inversora el control de la empresa objetivo en un futuro más o menos inmediato. Una vez realizada la adquisición inicial, se producen las adquisiciones posteriores o acumulaciones a través de las cuales la empre-

6 GROSSMAN y HART (1980), SHLEIFER y VISHNY (1986), HIRSHLEIFER y TITMAN (1990), CHOWDHRY y JEGADEESH (1994), RAVID y SPIEGEL (1999), BRIS (2002) y GOLDMAN y QIAN (2005).

${ }^{7} \mathrm{Si}$ bien la literatura apunta a un incremento de la probabilidad de desarrollar con éxito un proceso de adquisición total cuando la empresa inversora toma inicialmente una posición minoritaria o toehold; la evidencia empírica no permite verificar tal supuesto, ya que la mayor parte de procesos de adquisición se materializan sin que la empresa adquirente anticipe tal participación en la empresa objetivo. 
sa inversora adquiere nuevas participaciones en el capital de la empresa objetivo, completando, así, el proceso de adquisición de la empresa local. Si bien desde el punto de vista teórico resulta relativamente sencillo diferenciar un toehold de una inversión meramente financiera, no lo es tanto en la realidad, ya que el incremento de la participación en el capital de la empresa local puede estar previsto de antemano o puede ser una respuesta ante cambios acontecidos en el entorno o en los objetivos perseguidos por la propia empresa inversora ${ }^{8}$.

\subsection{El perfil del vendedor}

Tradicionalmente, en la literatura sobre elección de modos de entrada en nuevos mercados se analiza tal elección desde la perspectiva única del inversor extranjero, obviando algunos aspectos, tales como las características u objetivos perseguidos por el propietario inicial de las empresas locales que son vendidas, los cuales pueden influir de forma substancial en la fórmula finalmente elegida. Así, el tipo de propietario de la empresa local objeto de adquisición puede modificar substancialmente las características de la misma. Una primera distinción al respecto radica en el número de propietarios, ya que cabe diferenciar empresas locales que son propiedad de una única entidad, sea ésta familia, estado o grupo industrial, de aquellas empresas cuya propiedad está dispersa entre un elevado número de inversores, distinguiéndose en este último caso, empresas que cotizan en sus respectivos mercados de valores locales, frente a empresas que no lo hacen.

En el primer caso, la adquisición parcial debe ser entendida no sólo como un proyecto de inversión por parte de la adquirente, sino también como un proyecto de desinversión parcial por parte del propietario de la empresa objetivo, el cual puede preferir esta fórmula (frente a la desinversión o venta total) al objeto de apropiarse de una parte del incremento de valor que se derive del proceso de inversión e implicación en la gestión de la sociedad por parte del inversor extranjero.

En este contexto de propietario único, cabe distinguir entre empresas que son propiedad del estado y empresas que son privadas, ya que en el primer caso la adquisición se lleva a cabo vía procesos de privatización que, tal y como apunta Estrin (2002), pueden desarrollarse siguiendo diferentes modelos como la venta directa al inversor extranjero, la transferencia de la propiedad (o de parte de la misma) a los empleados de la empresa o la utilización de programas voucher que

${ }^{8}$ Caso aparte lo constituyen los denominaos toeholds externos u outsider toeholds (LINDQVIST, 2004a, 2004b) que implican la toma por parte de una empresa inversora de una participación minoritaria en el capital de una segunda empresa al objeto de beneficiarse del incremento de valor que tal participación pueda experimentar como consecuencia de la externalidad positiva derivada del proceso de adquisición de una tercera empresa rival de la empresa inicialmente participada. La lógica que subyace tras este proceso se basa en el hecho de que, en determinadas circunstancias, los procesos de adquisición o fusión entre empresas de un sector benefician en mayor medida a empresas rivales que compiten en el mismo sector que a las propias empresas implicadas (generación de una externalidad). 
facilitan la distribución de la propiedad entre amplios segmentos de la población 9 . En caso de que la venta se realice directamente por el gobierno o la agencia de privatización, la misma suele realizarse a través de un proceso de oferta competitiva. El hecho de que la empresa sea propiedad del estado o de los propios empleados puede introducir retos adicionales al inversor extranjero, ya que estos propietarios suelen plantearse objetivos relacionados con la transferencia de la empresa que van más allá de la mera maximización del valor que perciben por la participación que venden; antes al contrario, objetivos tales como la realización de inversiones en la propia empresa por parte del potencial adquirente y la protección de los puestos de trabajo tienden a erigirse en prioritarios para estos vendedores, particularmente en las economías susceptibles de ser calificadas como emergentes (Meyer y Jakobsen, 2007). En términos de Meyer (2002), la adquisición parcial es la fórmula que permite alinear los objetivos del inversor extranjero y el gobierno local en un proceso de privatización.

En tales circunstancias, la elección del modo de entrada no constituye una decisión unilateral del inversor extranjero, sino el resultado de una negociación entre las partes implicadas, en la cual la venta sólo parcial de la entidad privatizada constituye una forma de garantizar la influencia y salvaguardar los intereses de la parte vendedora. En este contexto suele ser habitual que en las propias condiciones del pliego de privatización se explicite cuál es la proporción de capital de la empresa susceptible de ser vendido, qué parte del mismo puede ser adquirido por inversores extranjeros, qué obligaciones contractuales asumen dichos inversores en relación con la realización de inversiones, mantenimiento de puestos de trabajo, si se mantiene, en su caso, acción de oro por parte del estado vendedor, etc. Adicionalmente, suele ser frecuente que el estado o agencia de privatización favorezca explícita o implícitamente la adjudicación a consorcios o grupos de empresas en los que tome parte alguna/s empresa/s locale/s. Todo ello limita la posibilidad real de elección de la empresa inversora respecto a la fórmula de implantación en el mercado receptor.

\footnotetext{
${ }^{9}$ Estos programas implican la distribución por parte del estado de certificados o cupones entre determinados segmentos de población; tales cupones son posteriormente canjeables por acciones de la compañía privatizada o por participaciones en intermediarios financieros. En la mayor parte de los casos, estos cupones pueden ser libremente transaccionados por sus propietarios.
} 
CUADRO 1

TIPOLOGÍA DE ADQUISICIONES PARCIALES ATENDIENDO A DIFERENTES CRITERIOS DE CLASIFICACIÓN

\begin{tabular}{|l|l|}
\hline \multicolumn{2}{|c|}{ Número de empresas adquirentes } \\
\hline Adquisiciones realizadas por un único inversor \\
\hline \multicolumn{2}{|c|}{ Porcentaje adquirido } \\
\hline Adquisiciones compartidas por varios inversores \\
\hline Adquisiciones mayoritarias & Adquisiciones dominantes \\
\hline Adquisiciones minoritarias & Adquisiciones no dominantes \\
\hline Toeholds & \\
\hline Estabilidad del capital adquirido & \\
\hline Adquisiciones puntuales & \\
\hline Adquisiciones escalonadas o en etapas & \\
\hline Perfil del vendedor & \\
\hline Propietario inicial único: estado \\
\hline Propietario inicial único: familia, empresa o grupo industrial \\
\hline Propietarios iniciales múltiples \\
\hline
\end{tabular}

\section{Evidencia empírica sobre las adquisiciones parciales internacionales realizadas por las empresas españolas}

\subsection{Base de datos y metodología}

Con objeto de realizar un primer estudio de carácter exploratorio sobre la utilización de las adquisiciones parciales como fórmula de implantación en los procesos de internacionalización mediante inversión directa de las empresas españolas, así como de identificar las pautas y contextos en que dicha fórmula constituye el modo de implantación elegido por tales empresas, se ha desarrollado un análisis empírico cuyos principales resultados se presentan a continuación. El período objeto de estudio abarca los años comprendidos entre 1988 y 2003, ambos incluidos, y la población objeto de estudio las empresas españolas admitidas a cotización oficial en la Bolsa de Madrid en cada uno de los años de dicho período. Al objeto de identificar las inversiones realizadas mediante adquisición por las empresas españolas se llevó a cabo un exhaustivo rastreo de la prensa económica utilizando en una primera fase la base de datos Baratz y, posteriormente, las hemerotecas de los diarios Expansión y Cinco Días, así como la de la revista Actualidad Económica. Una vez realizada 
una primera identificación de las inversiones por esta vía, se contrastó y completó la información relativa a las mismas mediante la consulta de los comunicados realizados por las empresas a la Comisión Nacional del Mercado de Valores (CNMV) y, en algunos casos, a través de las memorias anuales de las propias empresas. Las participaciones minoritarias (inferiores al 10\%) se incluyeron en la base de datos únicamente cuando la noticia recogía explícitamente el interés de la empresa española por desarrollar una internacionalización activa en el mercado receptor y/o cuando tal participación le permitía formar parte directa o indirectamente del órgano de administración de la participada o integrar el «núcleo duro» de accionistas de la misma ${ }^{10}$.

Este rastreo de prensa nos permitió identificar un total de 313 nuevos proyectos de inversión materializados a través de adquisiciones parciales de empresas locales realizados por un total de 61 empresas diferentes ${ }^{11}$. Identificamos como nuevos proyectos a las inversiones que suponen la primera toma de participación en la empresa local, prescindiendo, en un primer momento, de inversiones que suponen un incremento de la participación en un proyecto emprendido anteriormente. El $45 \%$ de estos proyectos se localizaron en países de América Latina, mientras que la Unión Europea (UE) y los restantes países OCDE -en adelante, países OCDE- integran un $50 \%$ de las inversiones identificadas. Los países de Europa del Este, Asia o África constituyen, por tanto, regiones en las que las empresas españolas apenas han invertido mediante la fórmula objeto de estudio en este trabajo; tendencia que, tal y como se apunta en la práctica totalidad de trabajos al respecto ${ }^{12}$, se constata para el conjunto de la inversión exterior española, al margen del modo de implantación elegido para materializar tales inversiones. Respecto a la tendencia temporal identificada, el grueso de los proyectos se concentra en el período comprendido entre la segunda mitad de los 90 y el comienzo de la década del 2000 -en la Figura 1 se recoge la evolución temporal de los proyectos identificados-. Según numerosos trabajos al respecto, parecen ser estos proyectos de adquisición parcial los que han contribuido en mayor medida al importante incremento que la IDE española ha experimentado en el mencionado período. Un porcentaje ligeramente inferior al $20 \%$ de estos proyectos respondió a procesos de privatización de empresas públicas. Tanto el elevado número de empresas considerado, como el amplio período de estudio analizado, conlleva la existencia de cierta heterogeneidad en la composición de la muestra cuando se considera la experiencia internacional de las empresas inversoras. Así, en la misma se recogen APs realizadas por empresas con una dilatada tra-

\footnotetext{
${ }^{10}$ Los Reales Decretos 672/1992 de 2 de Julio sobre inversiones españolas en el exterior y 664/1999 de 23 de Abril sobre inversiones exteriores. considera que son inversiones directas -frente a las inversiones meramente financieras- aquellas que proporcionen a la empresa inversora la capacidad de influir de manera efectiva en la gestión o control de la sociedad extranjera objeto de la inversión. Adicionalmente, se considera que dicha capacidad existe cuando la participación directa o indirecta de la primera en la segunda sea igual o superior al $10 \%$ del capital de la misma, o, cuando no alcanzándose dicho porcentaje, la participación proporcione a la empresa inversora el derecho a participar en el órgano de administración de la adquirida.

11 A tal efecto, hemos considerado una sola empresa a la empresa resultante de una fusión y a una de las empresas inicialmente independientes fusionada; por ejemplo, BBV y BBVA.

${ }^{12}$ Una revisión exhaustiva de la literatura al respecto se puede encontrar en DURÁN (2006).
} 
yectoria inversora en el exterior (en esta categoría tendrían cabida, por ejemplo, los proyectos realizados durante la segunda mitad de los 90 por empresas como Iberdrola, Endesa, Telefónica, Banco Santander o BBV), así como adquisiciones que constituyen bien un primer proyecto de inversión exterior, bien el primer proyecto que se materializa mediante adquisición parcial.

Una vez identificados los proyectos de nueva inversión, se llevó a cabo un segundo rastreo de prensa al objeto de identificar en cuántos de ellos la inversión identificada constituía únicamente un primer paso en un proyecto de superior envergadura. El rastreo realizado nos permitió identificar un total de 76 acumulaciones relacionadas con un total de 55 proyectos de nueva inversión recogidos en la primera base de datos. La totalidad de las mismas se localiza en países de América Latina $(55,26 \%$ de las acumulaciones), los países OCDE $(27,63 \%)$ y la Unión Europea $(17,0 \%)$. La distribución temporal, lógicamente dada la propia naturaleza de los proyectos, se aleja de la identificada para el conjunto de proyectos iniciales. Así, el $65 \%$ de las acumulaciones se concentran en los 5 últimos años del período objeto de estudio (1999-2003) -véase, de nuevo, la Figura 1.

\section{FIGURA 1}

EVOLUCIÓN TEMPORAL DE LAS APS EN EL PERÍODO OBJETO DE ESTUDIO

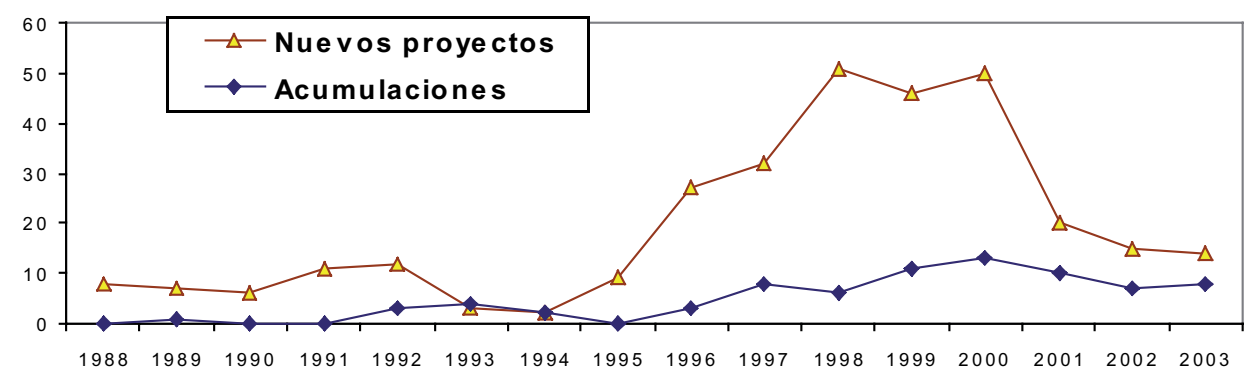

A continuación, se presentan los principales rasgos identificados para el conjunto de inversiones recogidas en la base de datos, clasificadas de acuerdo con la tipología de adquisiciones parciales anteriormente propuesta, así como las pautas de utilización de la fórmula de implantación objeto de estudio en este trabajo. La metodología utilizada al objeto de contrastar la existencia de relaciones entre las diferentes variables es la realización de tablas de contingencia, empleando el estadístico Chi-Cuadrado al objeto de contrastar la hipótesis de independencia (o asociación) entre los criterios de clasificación empleados. Dicho estadístico permite determinar si el comportamiento de las categorías de una variable presenta diferencias estadísticamente significativas, partiendo de la hipótesis de que los resultados de las categorías de una variable no se ven afectados o influenciados por las categorías de la segunda variable. La significación estadística de la Chi-Cuadrado per- 
mite rechazar la hipótesis nula de independencia de las variables consideradas. Por su parte, al objeto de estimar la fuerza de la asociación entre las variables (caso de no ser independientes), se han utilizado el test de los residuos tipificados, el coeficiente de contingencia y los estadísticos Phi y V de Cramer.

\subsection{Tipología de APs: número de empresas adquirentes y porcentaje de capital adquirido}

Según se ha mencionado anteriormente, en la categoría de adquisiciones parciales tiene cabida una amplia variedad de fórmulas de inversión. En relación con el porcentaje de capital adquirido por la inversora, en este trabajo hemos considerado la fórmula de clasificación que distingue entre adquisiciones mayoritarias, minoritarias y toeholds. Si bien el porcentaje de capital adquirido por la empresa inversora y el número de empresas adquirentes implicadas en el proceso constituyen dos criterios claramente diferenciados, hemos considerado necesario combinarlos para la realización del análisis empírico. Así, en las adquisiciones compartidas el porcentaje de capital adquirido en concreto por una de las empresas participantes en el proyecto puede ser menos relevante en tanto que la misma puede acceder al control de la empresa objetivo a través de la participación conjunta con los restantes socios. Combinando ambos criterios hemos procedido a identificar cuatro categorías de APs. La Figura 2 recoge evidencia al respecto.

\section{FIGURA 2}

\section{TIPOLOGÍA DE APS EN FUNCIÓN DEL NÚMERO DE ADQUIRENTES Y EL VOLUMEN DE CAPITAL ADQUIRIDO}
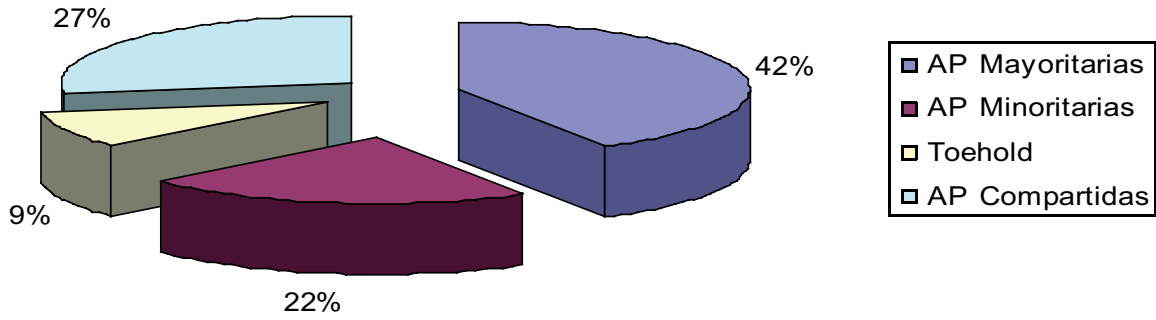

Tal y como se recoge en el gráfico, la mayor parte de las APs realizadas por las grandes empresas españolas en el período 1988-2003 son realizadas por un único inversor -en total, el $72 \%$ de las APs identificadas-. Dentro de éstas, hemos identificado, a su vez, tres categorías, en función del porcentaje del capital adquirido por el socio: AP Mayoritarias -la empresa inversora adquiere un porcentaje de capital de la sociedad adquirida superior al 50\%, pero inferior al 100\%-; AP Minoritarias -la empresa adquiere un porcentaje inferior al 50\%, si bien superior al $10 \%$ que establece la legislación ya mencionada- y las Toehold -la empresa adquiere un porcen- 
taje inferior al $10 \%$ del capital de la adquirente-. Tal y como se observa en la Figura 1, las AP Mayoritarias son la categoría más frecuente dentro de este grupo -en total, representan el $57 \%$ de las adquisiciones no compartidas.

Atendiendo a criterios tales como la localización, el sector de actividad y el tipo de vendedor, pretendemos identificar, a continuación, el perfil característico de cada uno de estos tipos de adquisición parcial. Adicionalmente, al objeto de contrastar en qué medida los resultados obtenidos están condicionados por el momento de realización de la inversión, hemos procedido a dividir la muestra en tres submuestras que corresponden a otras tantas tendencias en la evolución de la IDE española materializada mediante adquisiciones parciales (véase la Figura 1). Así, la primera de ellas recoge los proyectos realizados desde la fecha de comienzo del período objeto de estudio hasta 1994 -período en el que se constata un volumen anual de APs particularmente limitado (49 APs en todo el período)-. La segunda recoge los proyectos realizados en los que podríamos denominar el período del boom inversor exterior de las empresas españolas; es decir, 1995-2000 (215 APs). El tercero y último aglutina los proyectos realizados en el último trienio incluido en el período objeto de estudio, en el que se constata un importante decrecimiento en la actividad inversora en el exterior mediante APs de las empresas españolas (49 APs). Los diversos análisis relativos a las características del país receptor (grado de desarrollo económico, grado de riesgo país y distancia cultural respecto a España) y al perfil del vendedor a que hacen referencia los siguientes epígrafes, se han realizado para el conjunto de la muestra, siendo posteriormente repetidos para cada una de las tres submuestras indicadas ${ }^{13}$. Por razones de simplicidad, en los epígrafes que a continuación se presentan se muestran únicamente las tablas relativas al conjunto de la muestra, si bien se matizan los mismos atendiendo a los resultados parciales de cada una de las tres submuestras indicadas.

\section{LOCALIZACIÓN DE LAS ADQUISICIONES PARCIALES}

Al objeto de realizar un análisis de la localización de las APs identificadas en nuestra base de datos, hemos utilizado cuatro criterios de clasificación: el grado de desarrollo económico o industrialización del país receptor de la inversión, la agrupación de los países destino en una serie de bloques en función de su localización geográfica e integración en determinadas instituciones supranacionales, la distancia cultural existente entre las naciones inversora (España) y receptora, y el grado de riesgo país inherente a esta última.

En primer lugar, hemos clasificado las APs en función del grado de industrialización del país receptor. Para ello, hemos utilizado la clasificación que realiza el

\footnotetext{
${ }^{13}$ Los análisis relativos al sector de actividad y la región receptora no se realizaron sobre las submuestras debido a que el reducido tamaño de dos de ellas no permite la realización de un desglose estadísticamente significativo con tan elevado número de categorías.
} 
Banco Mundial al respecto. El mismo clasifica los diferentes países en cuatro categorías en función de que los mismos superen o no determinados umbrales de renta per capita que varían periódicamente. Así, las grandes empresas españolas han realizado un importante volumen de APs en los países de mayor renta per capita -países industriales en términos del Banco Mundial-, así como un volumen prácticamente nulo en los países menos desarrollados económicamente. Con todo, son los países en vías de desarrollo -países de renta per capita media-alta y media-baja- los que reciben un mayor porcentaje de las APs realizadas por estas empresas -más del $58 \%$ de las APs recogidas en la base-, resultado que es consistente por el encontrado por Ramirez y otros (2004) relativo al conjunto de la inversión exterior española (con independencia del modo de implantación empleado).

La Tabla 1 recoge evidencias respecto a la relación existente entre el tipo de AP y su localización según el grado de desarrollo económico del país receptor. La significación estadística de la Chi-Cuadrado nos permite rechazar la hipótesis nula de independencia entre el tipo de adquisición parcial elegido por la empresa inversora y el grado de desarrollo del país receptor de la inversión; los estadísticos Phi y V de Cramer, así como el coeficiente de contingencia presentan, asimismo, la máxima significación estadística.

TABLA 1

DISTRIBUCIÓN DE LAS APS EN FUNCIÓN DEL GRADO DE DESARROLLO ECONÓMICO DEL PAÍS RECEPTOR

\begin{tabular}{|c|c|c|c|c|c|}
\hline & $\begin{array}{c}\text { RPC } \\
\text { alta }\end{array}$ & $\begin{array}{c}\mathrm{RPC} \\
\text { media-alta }\end{array}$ & $\begin{array}{c}\text { RPC } \\
\text { media-baja }\end{array}$ & $\begin{array}{l}\text { RPC } \\
\text { baja }\end{array}$ & Total \\
\hline AP mayoritarias & $\begin{array}{c}56 \\
(0,9)\end{array}$ & $\begin{array}{c}42 \\
(-0,9)\end{array}$ & $\begin{array}{c}29 \\
(-0,5)\end{array}$ & $\begin{array}{c}3 \\
(2,1)\end{array}$ & $\begin{array}{c}130 \\
41,5 \%\end{array}$ \\
\hline AP minoritarias & $\begin{array}{c}22 \\
(-1,5)\end{array}$ & $\begin{array}{c}31 \\
(2,0)\end{array}$ & $\begin{array}{c}15 \\
(-0,3)\end{array}$ & $\begin{array}{c}0 \\
(-0,9)\end{array}$ & $\begin{array}{c}68 \\
21,7 \%\end{array}$ \\
\hline Toehold & $\begin{array}{c}23 \\
(4,5)\end{array}$ & $\begin{array}{c}4 \\
(-2,5)\end{array}$ & $\begin{array}{c}2 \\
(-2,2)\end{array}$ & $\begin{array}{c}0 \\
(-0,6)\end{array}$ & $\begin{array}{c}\mathbf{2 9} \\
\mathbf{9 , 3 \%}\end{array}$ \\
\hline AP compartidas & $\begin{array}{c}25 \\
(-2,5)\end{array}$ & $\begin{array}{c}33 \\
(0,7)\end{array}$ & $\begin{array}{c}28 \\
(2,3)\end{array}$ & $\begin{array}{c}0 \\
(-1,1)\end{array}$ & $\begin{array}{c}86 \\
27,5 \%\end{array}$ \\
\hline Total & $\begin{array}{c}126 \\
40,3 \%\end{array}$ & $\begin{array}{c}110 \\
35,1 \%\end{array}$ & $\begin{array}{c}74 \\
23,6 \%\end{array}$ & $\begin{array}{c}3 \\
1,0 \%\end{array}$ & $\begin{array}{c}313 \\
100 \%\end{array}$ \\
\hline
\end{tabular}

Chi Cuadrado $=32.12 * * *$ (residuos ajustados entre paréntesis).

Phi: $0,32 * * * \quad$ V de Cramer: $0,185^{* * *}$ Coeficiente de contingencia: $0.305^{* * *}$

$* \mathrm{p}<0,1 ; * * \mathrm{p}<0,05 ; * * * \mathrm{p}<0,01$

El valor de los residuos tipificados nos permite constatar, en primer lugar, que las toehold presentan una tendencia superior a la media a ser realizadas en el conjunto de países que presentan un mayor grado de desarrollo económico. Los países que 
integran este grupo reciben un porcentaje de toeholds superior al esperado, siendo la diferencia estadísticamente significativa; resultado éste que se mantiene cuando la muestra en desglosada atendiendo al momento de realización de la inversión. Por el contrario, se constata que la fórmula de la adquisición compartida se utiliza en este grupo de países con una frecuencia inferior a la constada para el conjunto de la muestra. Los datos apuntan a que esta última fórmula tiende a ser utilizada en mayor medida en los países del grupo 3 (grado de industrialización medio bajo), lo cual coincide con lo apuntado por Meyer y Estrin (2006) respecto a que ésta es una fórmula particularmente utilizada para materializar las inversiones en economías emergentes que presentan un elevado crecimiento o potencial de crecimiento, si bien carecen de un marco institucional equiparable al de los países más desarrollados económicamente. En este contexto, las capacidades necesarias para competir en el mercado local suelen ser contextuales o específicas del propio mercado receptor, lo que tiende a hacer necesaria la participación de un socio local que aporte las mismas. Cuando se divide la muestra atendiendo al momento de realización de las inversiones, este resultado presenta una superior significación estadística en el subperíodo 1995-2000, probablemente consecuencia de que en el mismo se aglutinan la mayor parte de las adquisiciones compartidas recogidas en la base de datos.

Si bien el número total de proyectos localizados en los países de menor grado de desarrollo económico es particularmente limitado (tan solo 3), llama la atención el hecho de que la totalidad de los mismos se ha materializado a través de una adquisición mayoritaria que garantiza a la empresa española el control sobre la gestión de la empresa adquirida.

En segundo lugar, hemos utilizado una clasificación similar a la utilizada por Delgado y otros (1999), agrupando los países en una serie de bloques en función de su localización geográfica e integración en determinadas instituciones supranacionales. En la Tabla 2 se presentan las principales evidencias respecto a las tendencias que presentan las diferentes categorías de APs identificadas en la base de datos a ser realizadas en cada uno estos bloques. El valor de todos los estadísticos estimados indica la existencia de dependencia entre las variables consideradas, con una significación estadística del 95\%. Observando los residuos tipificados que aparecen en la citada tabla, un primer resultado nos permite constatar que si bien las toehols se concentraban mayoritariamente en los países más desarrollados económicamente, según se apuntó anteriormente, es la Unión Europea (frente a los restantes países de la OCDE) la región que recibe un porcentaje de este tipo de inversiones significativamente superior al esperado. De igual forma, constatamos que es en los países emergentes de América Latina donde se concentran con una frecuencia superior a la constatada para el conjunto de la muestra las adquisiciones compartidas.

En tercer lugar, hemos analizado la localización en función del la distancia cultural entre los países emisor y receptor de las APs. Así, numerosos trabajos apuntan a la distancia cultural como factor que condiciona el modo de implantación utilizado en los procesos de internacionalización mediante inversión directa, ya que la misma constituye una aproximación a la denominada desventaja del extranjero a que 
se enfrentan las empresas inversoras -véanse, por ejemplo, Kogut y Singh (1988), Reuer y Koza (2000). En el caso concreto de la realización de adquisiciones, la literatura al respecto apunta al hecho de que una mayor distancia cultural incrementa los costes ex ante y ex post inherentes al proceso. Así, la distancia cultural puede derivar en un incremento de la asimetría de información inherente al proceso, dando lugar a un incremento de los costes preadquisición a que se enfrenta la empresa compradora (Balakrishnan y Koza, 1993; Chen y Hennart, 2004). De igual forma, la distancia cultural contribuye a dificultar los procesos de integración, lo que a su vez, deriva en un aumento de los costes post adquisición -Kogut y Singh (1988) y Woodcook y otros (1994), entre otros.

TABLA 2

\section{DISTRIBUCIÓN DE LAS APS EN FUNCIÓN DEL BLOQUE GEOGRÁFICO EN EL QUE SE REALIZAN}

\begin{tabular}{|c|c|c|c|c|c|c|c|}
\hline & UE & $\begin{array}{c}\text { América } \\
\text { Latina }\end{array}$ & $\begin{array}{l}\text { Resto } \\
\text { OCDE }\end{array}$ & $\begin{array}{l}\text { Europa } \\
\text { del Este }\end{array}$ & África & Asia & Total \\
\hline AP mayoritarias & $\begin{array}{c}38 \\
(0.3)\end{array}$ & $\begin{array}{c}56 \\
(-0,6)\end{array}$ & $\begin{array}{c}29 \\
(0,2)\end{array}$ & $\begin{array}{c}1 \\
(-0,3)\end{array}$ & $\begin{array}{c}4 \\
(1,3)\end{array}$ & $\begin{array}{c}2 \\
(-0,4)\end{array}$ & $\begin{array}{c}130 \\
41,5 \%\end{array}$ \\
\hline AP minoritarias & $\begin{array}{c}20 \\
(0,2)\end{array}$ & $\begin{array}{c}26 \\
(-1,3)\end{array}$ & $\begin{array}{c}17 \\
(0,7)\end{array}$ & $\begin{array}{c}0 \\
(-0,9)\end{array}$ & $\begin{array}{c}1 \\
(-0,3)\end{array}$ & $\begin{array}{c}4 \\
(2,7)\end{array}$ & $\begin{array}{c}68 \\
21,7 \%\end{array}$ \\
\hline Toehold & $\begin{array}{c}14 \\
(2,5)\end{array}$ & $\begin{array}{c}5 \\
(-3,2)\end{array}$ & $\begin{array}{c}9 \\
(1,3)\end{array}$ & $\begin{array}{c}1 \\
(1,4)\end{array}$ & $\begin{array}{c}0 \\
(-0,8)\end{array}$ & $\begin{array}{c}0 \\
(-0,8)\end{array}$ & $\begin{array}{c}29 \\
9,3 \%\end{array}$ \\
\hline AP Compartidas & $\begin{array}{c}17 \\
(-2,1)\end{array}$ & $\begin{array}{c}54 \\
(3,9)\end{array}$ & $\begin{array}{c}13 \\
(-1,7)\end{array}$ & $\begin{array}{c}1 \\
(0,2)\end{array}$ & $\begin{array}{c}1 \\
(-0,6)\end{array}$ & $\begin{array}{c}0 \\
(-1,5)\end{array}$ & $\begin{array}{c}86 \\
27.5 \%\end{array}$ \\
\hline Total & $\begin{array}{c}89 \\
28,4 \%\end{array}$ & $\begin{array}{l}141 \\
45 \%\end{array}$ & $\begin{array}{c}68 \\
21,7 \%\end{array}$ & $\begin{array}{c}3 \\
1 \%\end{array}$ & $\begin{array}{c}6 \\
1,9 \%\end{array}$ & $\begin{array}{c}6 \\
1,9 \%\end{array}$ & $\begin{array}{c}313 \\
100 \%\end{array}$ \\
\hline
\end{tabular}

Chi Cuadrado $=33,67 * *$ (residuos ajustados entre paréntesis)

Phi: $0,328 * *$ V de Cramer: 0,189** Coeficiente de contingencia: $0,312 * *$ $* \mathrm{p}<0,1 ; * * \mathrm{p}<0,05 ; * * * \mathrm{p}<0,01$.

Al objeto de medir la distancia cultural existente entre España y cada una de las naciones receptoras, hemos optado por utilizar un índice compuesto a partir de las 9 dimensiones de distancia cultural identificadas y medidas en un reciente estudio en el marco del proyecto GLOBE (House y otros, 2004). Dicho estudio constituye un proyecto de naturaleza multinacional desarrollado a partir de información recogida al efecto para un total de 62 sociedades diferentes. El mismo identifica un total de 9 atributos o dimensiones culturales relacionadas tanto con aspectos sociales como organizacionales, a saber, grado de asertividad, colectivismo institucional, colectivismo de grupo, orientación al futuro, igualdad de género, orientación a las personas, orientación al resultado, distancia al poder y aversión a la incertidumbre. El estudio cuantifica tanto valores como prácticas relacionadas con estas 9 dimensio- 
nes en cada país -en este sentido, los valores culturales se han construido a partir de las respuestas a cuestionarios del tipo «así deberían ser los comportamientos», mientras que las prácticas se han construido a partir de cuestionarios del tipo «así son los comportamientos»-. Al objeto de recoger la distancia cultural entre España y cada una de las naciones receptoras ${ }^{14}$, hemos procedido a elaborar un índice basado en las desviaciones calculadas entre ambos países para cada una de las 9 dimensiones identificadas. Se han utilizado, en concreto, las medidas relativas a las prácticas, ya que, tal y como se recoge en el propio estudio, éstas reflejan en mayor medida la realidad actual de los comportamientos de las personas y empresas de una nación. La representación algebraica del índice es la siguiente:

$$
\mathrm{DC}_{\mathrm{j}}=\sum_{\mathrm{i}=1}^{\mathrm{i}=9}\left[\left(\mathrm{I}_{\mathrm{ij}}-\mathrm{I}_{\mathrm{is}}\right) / \mathrm{V}_{\mathrm{i}}\right] / 9
$$

Donde $\mathrm{DC}_{\mathrm{j}}$ es la distancia cultural entre España y el país $\mathrm{j}$; $\mathrm{I}_{\mathrm{ij}}$ representa el índice de la dimensión cultural i y el país j; s representa España y $\mathrm{V}_{\mathrm{i}}$ representa el valor de la varianza del índice en la dimensión i. Si bien dicho índice calculado constituye un continuo, y los propios autores del proyecto no establecen un valor absoluto para cada dimensión a partir del cual se pueda considerar que dos naciones son o no distantes culturalmente, sí resulta posible ordenar los países destino de las APs españolas en función de su distancia cultural respecto a España. A tal efecto, optamos por dividir nuestra muestra inicial de inversiones en dos categorías utilizando para ello el valor mediano de la distancia cultural de los diferentes países receptores respecto a España. La Tabla 3 muestra los resultados obtenidos para los diferentes tipos de adquisición parcial en función de esta clasificación; de nuevo el valor de los diferentes estadísticos considerados -Chi-Cuadrado, Phi, V de Cramer y Coeficiente de Contingencia- permite rechazar la hipótesis nula de independencia entre las dos variables consideradas con una significación estadística del 99\%.

Los resultados muestran que las adquisiciones parciales mayoritarias y los toeholds son utilizados por las empresas españolas con una frecuencia superior a la observada para el conjunto de la muestra en los países que muestran una mayor distancia cultural respecto a España. Al dividir la muestra en tres subperíodos diferenciados, este resultado mantiene su significación estadística únicamente para el subperíodo 95-00. En relación con los toeholds, estos resultados parecen confirmar el papel que este tipo de participaciones juegan como fórmula que permite a la empresa inversora acceder a información de la empresa objetivo - y reducir, así, la asimetría de información existente entre ambas - antes de implicarse en una adquisición total o mayoritaria que implique un mayor compromiso de recursos.

\footnotetext{
${ }^{14} \mathrm{El}$ proyecto GLOBE no incorpora información para todas las naciones, si bien las clasifica a priori-es decir, antes de realizar las mediciones de las citadas 9 dimensiones- en un total de 10 clusters. Por ello, para aquellos países para los que no existían datos optamos por asignarles la media aritmética de la distancia cultural calculada para el conjunto de países integrantes del cluster en el cual consideramos razonable enmarcar la citada nación -por ejemplo, Perú y Chile son dos naciones no analizadas en el citado proyecto, si bien son países receptores de inversión en nuestro trabajo. A tal efecto, consideramos razonable enmarcarlas en el cluster de América Latina y posteriormente asignarles el valor medio de la distancia cultural de las naciones de dicho cluster.
} 
TABLA 3

DISTRIBUCIÓN DE LAS APS EN FUNCIÓN DE LA DISTANCIA CULTURAL CON EL PAÍS RECEPTOR

\begin{tabular}{|c|c|c|c|}
\hline & Menor DC & Mayor DC & Total \\
\hline \multirow{2}{*}{ AP mayoritarias } & 62 & 68 & $\mathbf{1 3 0}$ \\
& $(-2,6)$ & $(2,6)$ & $\mathbf{4 1 , 5 \%}$ \\
\hline \multirow{2}{*}{ AP minoritarias } & 43 & 25 & $\mathbf{6 8}$ \\
& $(1,3)$ & $(-1,3)$ & $\mathbf{2 1 , 7 \%}$ \\
\hline Toehold & 9 & 20 & 29 \\
& $-(2,9)$ & $(\mathbf{2 , 9})$ & $\mathbf{9 , 3 \%}$ \\
\hline \multirow{2}{*}{ AP compartidas } & 62 & $(24)$ & 86 \\
& $(3,5)$ & $(-\mathbf{3 , 5})$ & $\mathbf{2 7 , 5 \%}$ \\
\hline Total & $\mathbf{1 7 6}$ & $\mathbf{1 3 7} 15$ & $\mathbf{3 1 3}$ \\
& $\mathbf{5 6 , 2 \%}$ & $\mathbf{4 3 , 8 \%}$ & $\mathbf{1 0 0 \%}$ \\
\hline
\end{tabular}

Chi Cuadrado $=21.48 * * *$ (residuos ajustados entre paréntesis)

Phi: $0,262 * * *$ V de Cramer: $0,262 * * *$ Coeficiente de contingencia: $0,253 * * *$

$* \mathrm{p}<0,1 ; * * \mathrm{p}<0,05 ; * * * \mathrm{p}<0,01$.

Por otro lado, la realización de una adquisición mayoritaria supone para la empresa inversora unas implicaciones, respecto al control y participación en la toma de decisiones, que puede asimilarse a las de una adquisición total. Nuestro resultado parece confirmar lo recogido en algunos trabajos -véase, por ejemplo, López-Duarte y García-Canal (2002) - en los que se apunta al hecho de que la realización de una adquisición parcial que no proporcione a la empresa inversora el control efectivo de la sociedad adquirida constituye el modo de entrada menos adecuado en contextos de elevada distancia cultural, ya que tal fórmula obliga a la inversora a compartir la gestión con socios cuyas rutinas organizativas y pautas de comportamiento resultan muy diferentes, hecho susceptible de derivar, a su vez, en conflictos de intereses entre los socios y problemas de integración entre los mismos. También los trabajos de Meyer y Estrin (2006) y Meyer y Tran (2006) apuntan en esta dirección; estos autores constatan que los procesos de adquisición parcial en los que la adquirente no se hace con una participación que le permita controlar la empresa objetivo pueden dar lugar a mayores conflictos de intereses entre los socios -el proceso de toma de decisiones resulta mucho más sencillo para la inversora cuando no hay otros inversores con los que consultar, compartir información o ser integrados-, incrementándose la probabilidad de tal conflicto cuando existen fuertes diferencias en la identidad de los socios.

${ }^{15}$ La utilización del valor mediano para dividir la muestra debería conducir a la obtención de dos submuestras de igual tamaño. No obstante, en este caso la mediana corresponde a un dato que se reitera en numerosas ocasiones en la muestra. A tal efecto, hemos considerado razonable incluir todas las observaciones que presentan un mismo valor en una misma submuestra, lo que conduce a que una de las submuestras registre un número de observaciones sensiblemente superior. 
Si bien numerosos trabajos apuntan, en general, a las fórmulas que implican propiedad compartida (adquisiciones parciales y empresas conjuntas) como las adecuadas en entornos de elevada distancia cultural, parece constatarse que la probabilidad de conflicto de intereses en tales contextos es superior en el caso de las adquisiciones parciales que en el caso de la creación de una nueva empresa de propiedad compartida (Meyer y Tran, 2006; Ruiz Moreno y otros, 2007), lo cual se debe, al menos en parte, a que en el primer caso no existe un contrato explícito y consensuado por ambas partes en el que se especifiquen los objetivos y obligaciones concretos de cada uno de los socios.

Adicionalmente, tal y como punta Madhok (1997), la habilidad del personal de la empresa adquirida para absorber y explotar el know how y las rutinas de la empresa inversora disminuye cuando aumenta la distancia cultural entre los socios. Dicha distancia condiciona las actitudes de los trabajadores, los estilos de dirección, las pautas de toma de decisiones y las rutinas organizativas, introduciendo un factor de incertidumbre tanto para el equipo gestor de la empresa adquirente, como para el de la adquirida (Drug y Hagerty, 1997). Así, al objeto de controlar dicha incertidumbre, la empresa inversora tenderá, con una mayor probabilidad, a sustituir al equipo directivo de la empresa adquirida; por otro lado, ante la incertidumbre que para este equipo directivo supone la necesaria adaptación a los cambios impuestos por el inversor o el desconocimiento sobre el papel que jugará en el futuro de la empresa, incrementará la probabilidad de que el mismo opte por abandonar su puesto. Cuando la empresa inversora carece del control efectivo para realizar este cambio y debe consensuarlo con socios locales, el conflicto entre ambas partes puede agravarse de forma considerable (López Duarte y García-Canal, 2002).

Las adquisiciones compartidas, por su parte, parecen enmarcarse en países que presentan una menor distancia cultural respecto a España. Si bien no es irrelevante, este dato debe ser analizado en el contexto propio de esta fórmula de inversión, ya que en este caso un factor particularmente relevante es no sólo la distancia cultural entre las naciones emisora y receptora de la inversión, sino la distancia cultural existente entre las naciones de las diferentes empresas socio que han de coordinarse al objeto de materializar la inversión, así como entre cada una de estas y la nación receptora. Es por ello que la distancia recogida en este análisis es un dato únicamente parcial.

Finalmente, hemos analizado la localización en función del riesgo país. El riesgo país relativo a las diferentes naciones receptoras de las APs realizadas por empresas españolas se midió mediante los rankings elaborados por Euromoney para cada uno de los años incluidos en el período objeto de estudio ${ }^{16}$. La medida de riesgo país

\footnotetext{
${ }^{16}$ Para realizar este análisis hemos tenido que prescindir de 12 adquisiciones parciales para las que no disponíamos de datos de riesgo país homogeneizados respecto al resto de observaciones. Así, 4 observaciones corresponden a inversiones realizadas en Puerto Rico, Estado Libre Asociado de los Estados Unidos: tal consideración conlleva el que el mismo no sea un estado plenamente anexionado e EE.UU., al tiempo que no constituye una nación independiente, por lo que no existen índices de riesgo país específicos para el mismo. Las restantes observaciones corresponden a inversiones realizadas en 1988. Dado que la forma de medida de los índices de Euromoney experimentó un cambio en 1989, los datos disponibles para el año 88 no son homogéneos con los del resto de la muestra.
} 
incluida en estos rankings es una medida integradora en la que se acumulan en una sola medida el riesgo político, económico y financiero de cada país. La medida oscila entre 0 (mayor riesgo país) y 100 (menor riesgo país o mayor estabilidad). Al igual que sucedía con la distancia cultural anteriormente analizada, dicho índice calculado constituye un continuo, de forma que no resulta posible establecer un valor absoluto a partir del cual se pueda considerar que una nación tiene un elevado índice de riesgo. Por ello, hemos optado por dividir nuestra muestra inicial de adquisiciones parciales en dos categorías utilizando para ello el valor mediano del riesgo país de las naciones receptoras. La Tabla 4 muestra los resultados obtenidos para los diferentes tipos de adquisición parcial en función de esta clasificación, pudiendo rechazarse, de nuevo con una significación estadística superior al 99\%, la hipótesis de independencia de las variables.

TABLA 4

DISTRIBUCIÓN DE LAS APS EN FUNCIÓN DEL RIESGO PAÍS DEL MERCADO RECEPTOR

\begin{tabular}{|c|c|c|c|}
\hline & Mayor riesgo & Mayor estabilidad & Total \\
\hline AP mayoritarias & 60 & 66 & $\mathbf{1 2 6}$ \\
& $(-0.8)$ & $(0.8)$ & $\mathbf{4 1 . 9 \%}$ \\
\hline AP minoritarias & 32 & 35 & $\mathbf{6 7}$ \\
& $(-0.5)$ & $(0.5)$ & $\mathbf{2 2 . 3 \%}$ \\
\hline Toehold & 5 & 19 & $\mathbf{2 4}$ \\
& $(-3.0)$ & $(3.0)$ & $\mathbf{8 \%}$ \\
\hline AP compartidas & 55 & 29 & $\mathbf{8 4}$ \\
& $(3.2)$ & $(-3.2)$ & $\mathbf{2 7 . 9 \%}$ \\
\hline Total & $\mathbf{1 5 2}$ & $\mathbf{1 4 9}$ & $\mathbf{3 0 1}$ \\
& $\mathbf{5 0 . 5 \%}$ & $\mathbf{4 9 . 5 \%}$ & $\mathbf{1 0 0 \%}$ \\
\hline
\end{tabular}

Chi Cuadrado $=16.61 * * *$ (residuos ajustados entre paréntesis)

Phi: $0,235 * * *$ V de Cramer: 0,235*** Coeficiente de contingencia: 0,229***

$* \mathrm{p}<0,1 ; * * \mathrm{p}<0,05 ; * * * \mathrm{p}<0,01$.

El valor de los residuos ajustados muestra que las adquisiciones compartidas presentan una tendencia superior a la media a ser realizadas en países que presentan un mayor riesgo -resultado que mantiene su significación estadística en los diferentes subperíodos, excepto para el último trienio considerado-. Se trata de un resultado esperado en la medida que la creación de empresas conjuntas resulta en muchos

\footnotetext{
${ }^{17}$ Véase la nota a pie de página número 11.
} 
casos una condición necesaria para establecerse en aquellos países que presentan un elevado riesgo político (Lecraw, 1984; Kobrin, 1987) y, como ya se ha puesto de manifiesto en trabajos anteriores, las adquisiciones compartidas presentan pautas de utilización que se asemejan en mayor medida a las de las empresas conjuntas que a las de las adquisiciones, sean éstas totales o parciales (López-Duarte y GarcíaCanal, 2002).

Tal y como apuntan Meyer y Tran (2006) y Jackobsen y Meyer (2007) una superior distancia institucional entre las naciones inversora y receptora aumenta la asimetría de información entre las partes implicadas en el proceso de adquisición, haciendo más necesaria la participación en el mismo de un socio local que cuente con contactos, contribuyendo a mitigar tal asimetría. Adicionalmente, la elevada volatilidad en el país destino -que afecta a cambios en las instituciones, en la estructura industrial de los diferentes sectores e, incluso, a las variables macroeconómicas de la nación- incrementa el grado de exposición al riesgo de la empresa inversora, lo que, de nuevo, conduce a la necesidad de compartir los grandes proyectos de inversión con otros socios, particularmente locales.

\section{Distribución sectorial}

Por lo que respecta a la distribución sectorial, hemos optado por clasificar las APs recogidas en nuestra base de datos utilizando la Clasificación Nacional de Actividades Económicas (CNAE 93), con un desglose de dos dígitos -hemos introducido la modificación de unir en una misma categoría que denominamos Sector Financiero las actividades de banca e intermediación financiera y de seguros y de planes de pensiones. Tres sectores de actividad aglutinan casi el 60\% de las APs recogidas en la base de datos: el Sector Financiero, que es el que registra una mayor actividad con un 25\% del conjunto de APs; el sector Energía y Agua con un 18\% y, finalmente, el de Telecomunicaciones que representa el 15\% de las APs identificadas. Estas tendencias son consistentes con las encontradas en trabajos previos para el conjunto de la IDE española ${ }^{18}$. Al objeto de analizar la relación existente entre el tipo de AP y el sector de actividad, hemos agrupado las APs identificadas en la base de datos en cinco grandes sectores de actividad: Manufacturas; Construcción; Sectores Regulados -recoge las APs integradas en sectores tradicionalmente regulados que han sido objeto de una creciente liberalización, como el transporte aéreo, comunicaciones, energía y agua (OCDE, 1993)-, Servicios Financieros y Otros Servicios. La Tabla 5 recoge evidencia al respecto.

\footnotetext{
${ }^{18}$ En DURÁN (2006) puede encontrarse una exhaustiva revisión de la literatura al respecto.
} 
TABLA 5

DISTRIBUCIÓN DE LAS APS EN FUNCIÓN DEL SECTOR DE ACTIVIDAD

\begin{tabular}{|c|c|c|c|c|c|c|}
\hline & $\begin{array}{l}\text { Manufac- } \\
\text { turas }\end{array}$ & $\begin{array}{l}\text { Construc- } \\
\text { ción }\end{array}$ & $\begin{array}{c}\text { Sectores } \\
\text { regulados }\end{array}$ & $\begin{array}{l}\text { Servicios } \\
\text { financieros }\end{array}$ & $\begin{array}{c}\text { Otros } \\
\text { servicios }\end{array}$ & Total \\
\hline AP mayoritarias & $\begin{array}{c}42 \\
(3,0)\end{array}$ & $\begin{array}{c}7 \\
(-0,2)\end{array}$ & $\begin{array}{c}24 \\
(-4,6)\end{array}$ & $\begin{array}{c}30 \\
(-0,7)\end{array}$ & $\begin{array}{c}27 \\
(3,8)\end{array}$ & $\begin{array}{c}130 \\
41,5 \%\end{array}$ \\
\hline AP minoritarias & $\begin{array}{c}20 \\
(1,3)\end{array}$ & $\begin{array}{c}6 \\
(1,2)\end{array}$ & $\begin{array}{c}19 \\
(-1,0)\end{array}$ & $\begin{array}{c}19 \\
(0,6)\end{array}$ & $\begin{array}{c}4 \\
(-1,9)\end{array}$ & $\begin{array}{c}68 \\
21,7 \%\end{array}$ \\
\hline Toehold & $\begin{array}{c}0 \\
(-3,1)\end{array}$ & $\begin{array}{c}1 \\
(-0,6)\end{array}$ & $\begin{array}{c}8 \\
(-0,6)\end{array}$ & $\begin{array}{c}18 \\
(4,8)\end{array}$ & $\begin{array}{c}2 \\
(-1,0)\end{array}$ & $\begin{array}{c}29 \\
\mathbf{9 , 3 \%}\end{array}$ \\
\hline AP compartidas & $\begin{array}{c}12 \\
(-2,5)\end{array}$ & $\begin{array}{c}4 \\
(-0,5)\end{array}$ & $\begin{array}{c}52 \\
(6,4)\end{array}$ & $\begin{array}{c}12 \\
(-2,8)\end{array}$ & $\begin{array}{c}6 \\
(-1,8)\end{array}$ & $\begin{array}{c}86 \\
27,5 \%\end{array}$ \\
\hline Total & $\begin{array}{c}74 \\
23,6 \%\end{array}$ & $\begin{array}{c}18 \\
5,8 \%\end{array}$ & $\begin{array}{c}103 \\
32,9 \%\end{array}$ & $\begin{array}{c}79 \\
25,2 \%\end{array}$ & $\begin{array}{c}39 \\
12,5 \%\end{array}$ & $\begin{array}{c}313 \\
100 \%\end{array}$ \\
\hline
\end{tabular}

Chi Cuadrado $=78,52 * * *$ (residuos ajustados entre paréntesis).

Phi: $0,501 * * *$ V de Cramer: $0.289 * * * \quad$ Coeficiente de contingencia: $0.448 * * *$

$* \mathrm{p}<0,1 ; * * \mathrm{p}<0,05 ; * * * \mathrm{p}<0,01$.

Tal como se observa en la Tabla 5, existe una relación de dependencia entre el tipo de AP y el sector de actividad en el que se enmarca la empresa inversora estadísticamente significativa al 99\%. El valor de los residuos ajustados muestra la existencia de una tendencia superior a la media a que las AP Mayoritarias se realicen en el sector de las manufacturas y en servicios no financieros. Por su parte, las toehold presentan una propensión superior a la media a ser la fórmula de adquisición utilizada en el sector financiero. Tal y como se recoge en el trabajo de Guillén y Tschoegl (2002), en el sector financiero español la decisión de inversión puede estar condicionada por la necesidad de reaccionar ante las IDEs realizadas previamente por un competidor o por la necesidad de anticiparse a éstas. En este sentido, las toehold constituyen una vía rápida y menos arriesgada que otras fórmulas de inversión directa para acceder inicialmente al capital de la empresa objetivo. Este resultado es consistente con el obtenido anteriormente para la localización en función de la agrupación en determinados bloques supranacionales -véase la Tabla 2-. Así, las toehold presentan una tendencia superior a la media a utilizarse para acceder a los países de la UE, dónde precisamente las empresas del sector financiero han tenido que posicionarse para responder rápidamente a los cambios en el status quo competitivo.

Finalmente, cabe destacar que las adquisiciones compartidas tienen una tendencia superior a la media a ser la vía utilizada para acceder a sectores regulados. Estos sectores, como ya se ha señalado, vienen siendo objeto de una creciente liberalización, de forma que muchos de ellos han sido objeto de privatizaciones y desregulaciones en los últimos años. En particular, en América Latina resulta muy elevado 
el peso de la IDE realizada en un reducido número de sectores de actividad tradicionalmente regulados. Buena parte de estas inversiones responden a los procesos de liberalización y privatización que han tenido lugar en la región, lo que condiciona que la fórmula de inversión utilizada haya sido en mayor medida la adquisición compartida -cómo ya se ha evidenciado anteriormente; véase a este respecto la Tabla 2-. En ese sentido, cabe señalar que Campa y Guillen (1996) y Guillen (2004) identifican en sus trabajos un grupo de empresas españolas inversoras en el exterior que compiten en sectores oligopolísticos cuyo principal activo es la experiencia que han logrado acumular desarrollando sus respectivas actividades en España y operando en un entorno particularmente protegido, siendo este el activo en el que basan su proyección internacional. Uno de los activos fundamentales con que cuentan estas empresas es la experiencia acumulada en el trato y la relación con los gobiernos en entornos regulados en su propio país de origen (Henisz, 2003), activo susceptible de explotación cuando estas empresas se internacionalizan hacia países menos desarrollados económicamente que acometen las primeras fases de desregulación en los mencionados sectores, así como de privatización de sus empresas (frecuentemente monopolios) públicas. En este sentido, y según se ha apuntado, la aportación del socio local tiende a ser el conocimiento específico del mercado receptor.

\subsection{Tipología de APs: perfil del vendedor}

Una vez analizado el perfil de las adquisiciones parciales incluidas en los primeros criterios de clasificación propuestos en el Cuadro 1 del presente trabajo, procedemos a continuación a presentar las principales evidencias encontradas en nuestra base de datos para el siguiente criterio-aquél que las clasificaba en función del tipo de vendedor. En este sentido, cabe destacar el resultado (estadísticamente significativo al $99 \%$ y consistente en todos los subperíodos considerados cuando se divide la muestra) de la Tabla 6 que muestra como las adquisiciones parciales que responden a procesos de privatización de empresas públicas parecen inequívocamente vinculados a la fórmula de adquisiciones compartidas. Así, esta fórmula presenta una frecuencia superior a la observada para el conjunto de la muestra (resultado la diferencia estadísticamente significativa) cuando la inversión se vincula al mencionado proceso de privatización de una empresa inicialmente propiedad del estado. Tal y como se ha mencionado previamente, resulta frecuente que el estado o agencia privatizadora favorezca, o incluso exija, la participación de grupos o consorcios de empresas al objeto de garantizar la viabilidad del proceso - dado el elevado volumen de inversión que requieren tales proyectos, resulta difícil que una empresa pueda implicarse en solitario en los mismos. Adicionalmente, la participación de un grupo de empresas puede obedecer al hecho de que el estado o agencia exija la presencia de un socio local que comparta el proyecto con el/los inversor/es extranjero/s. 
TABLA 6

DISTRIBUCIÓN DE LAS APS EN FUNCIÓN DEL TIPO DE VENDEDOR

\begin{tabular}{|c|c|c|c|}
\hline & No privatización & Privatización & Total \\
\hline AP mayoritarias & 120 & 10 & $\mathbf{1 3 0}$ \\
& $(3,8)$ & $(-3,8)$ & $\mathbf{4 1 , 5 \%}$ \\
\hline AP minoritarias & 60 & 8 & $\mathbf{6 8}$ \\
& $(1,4)$ & $(-1,4)$ & $\mathbf{2 1 , 7 \%}$ \\
\hline Toehold & $\mathbf{2 7}$ & 2 & $\mathbf{2 9}$ \\
& $(1,5)$ & $(-1,5)$ & $\mathbf{9 . 3 \%}$ \\
\hline AP compartidas & 52 & 34 & $\mathbf{8 6}$ \\
& $(-6,4)$ & $(6,4)$ & $\mathbf{2 7 , 5 \%}$ \\
\hline Total & $\mathbf{2 5 9}$ & $\mathbf{5 4}$ & $\mathbf{3 1 3}$ \\
& $\mathbf{8 2 , 7 \%}$ & $\mathbf{1 7 , 3 \%}$ & $\mathbf{1 0 0 \%}$ \\
\hline
\end{tabular}

Chi Cuadrado $=41,85^{* * *}$ (residuos ajustados entre paréntesis),

Phi: $0,366^{* * *}$ V de Cramer: 0,366*** Coeficiente de contingencia: 0,343***

$* \mathrm{p}<0,1 ; * * \mathrm{p}<0,05 ; * * * \mathrm{p}<0,01$.

\subsection{Tipología de adquisiciones parciales: Estabilidad de la participación}

Tal y como se ha mencionado previamente, el segundo rastreo de prensa realizado con objeto de identificar las acumulaciones nos permitió identificar un total de 76 inversiones relacionadas con un total de 55 proyectos de nueva inversión recogidos en la primera base de datos. Ello implica que apenas un $18 \%$ de los proyectos recogidos en nuestra base de datos de primeras inversiones se corresponden con las denominadas adquisiciones escalonadas o en etapas. Por el contrario, parece que más del $80 \%$ de las adquisiciones parciales identificadas responden a un perfil de estabilidad en el capital de la empresa participada por parte de la empresa inversora.

Según aparece recogido en la Figura 3, el grueso de estas acumulaciones se materializó a través de adquisiciones no mayoritarias -así, un porcentaje cercano al $85 \%$ de estas acumulaciones se materializó a través de tomas de participación inferiores al 50\% del capital de la empresa objetivo, respondiendo casi la mitad de este porcentaje a tomas de porcentajes inferiores al $10 \%$ de dicho capital-. Un porcentaje ligeramente superior al 13\% de los casos responde a acumulaciones en las que la empresa inversora se hace con más del 50\% de la empresa objetivo en el proceso de acumulación, resultando mínimo, aunque no inexistente, el porcentaje de acumulaciones realizadas conjuntamente por varias empresas inversoras. 
FIGURA 3

APS ESCALONADAS: ACUMULACIONES EN FUNCIÓN DEL PORCENTAJE DE CAPITAL ADQUIRIDO
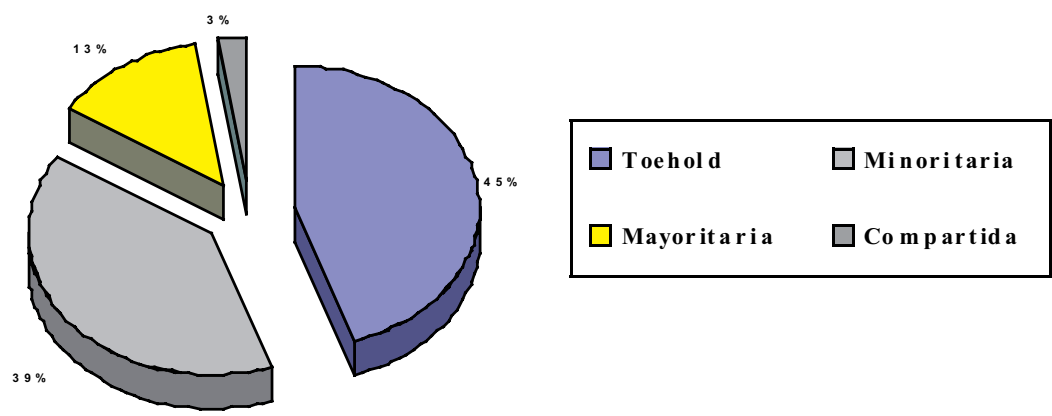

Un volumen cercano a un tercio de estos proyectos de acumulación parece responder al deseo de la empresa inversora de pasar de una posición minoritaria a mayoritaria en el capital de la empresa participada; mientras que un porcentaje cercano al 20\% implicó el que la empresa inversora pasara a controlar la totalidad de la empresa localizada en el mercado receptor (en la mayor parte de los casos partiendo de una posición inicial ya mayoritaria) ${ }^{19}$.

Resulta sorprendente, no obstante, que buena parte de los proyectos iniciales vinculados a una acumulación posterior no corresponden a la fórmula esperada, es decir a la inversión mediante lo que hemos definido como un toehold; antes al contrario, tan sólo un $21,4 \%$ de los 55 proyectos en los que se registró un incremento posterior en la participación de la empresa inversora responden a dicha fórmula. Tal como se observa en la Figura 4, cabe mencionar, no obstante, que otro porcentaje similar responde a situaciones en que la inversión inicial no podía ser catalogada como mayoritaria, a pesar de superar el umbral de participación que hemos considerado para definir los toeholds. Un $20 \%$ de los casos corresponde a proyectos en los que la inversora española ya adquirió inicialmente más del 50\% del capital de la empresa local, si bien ha optado en un momento posterior por incrementar dicha participación hasta un umbral superior.

El caso de acumulación más frecuente $(36,4 \%$ de los casos) corresponde a proyectos en los que la primera inversión se materializó a través de lo que hemos calificado como inversiones compartidas o realizadas conjuntamente por varias empresas inversoras, en las que una reordenación posterior de los porcentajes inicialmente tomados por las diferentes empresas implicadas o el abandono de algunas de ellas conduce a incremento de la participación de la empresa inversora identificada en la base de datos. Más de la mitad de estos casos se asocian con procesos de privatización en los que la empresa inversora se hace con la participación de alguna otra empresa o inversor igualmente posicionado en el proceso inicial.

\footnotetext{
19 Tan sólo el 10\% de las acumulaciones se llevó a cabo mediante la realización de una OPA lanzada a accionistas minoritarios.
} 
FIGURA 4

\section{ADQUISICIONES ESCALONADAS: TIPOLOGÍA INICIAL EN FUNCIÓN DEL VOLUMEN DE CAPITAL ADQUIRIDO Y EL NÚMERO DE ADQUIRENTES}

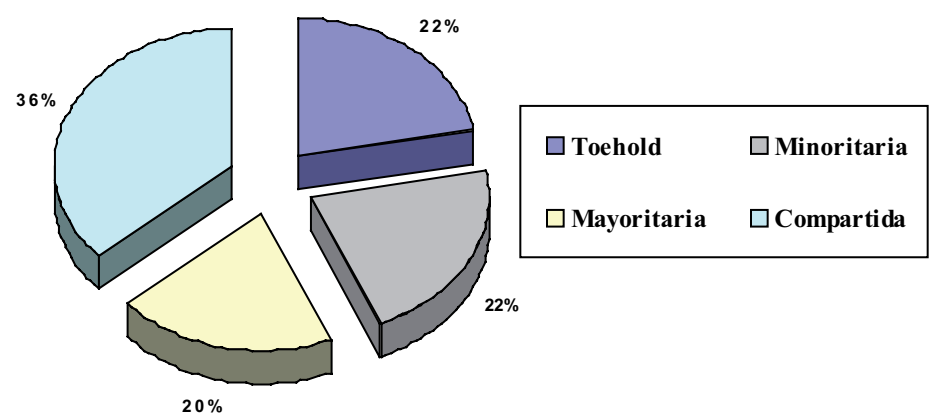

Haciendo a la inversa el análisis de estos datos, observamos que tan sólo un porcentaje aproximado del $40 \%$ de los toeholds inicialmente identificados dieron lugar a un proceso de acumulación posterior (porcentaje que se reduce a un escaso $25 \%$ si consideramos conjuntamente las inversiones calificadas como toeholds y adquisiciones minoritarias en la muestra inicial).

En principio, podría parecer éste un resultado extraño en tanto que las adquisiciones de capital iniciales inferiores al 10\% fueron incluidas en la base de datos únicamente cuando dicha toma iba aparejada a un interés explícito de la empresa española por desarrollar una internacionalización activa en el mercado receptor y/o cuando tal participación le permitía formar parte directa o indirectamente del órgano de administración de la participada. Así, en un principio, cabría esperar que la mayor parte de estas participaciones hubieran evolucionado hacia tomas de participación de mayor envergadura y no se constatara tal evolución tan sólo en aquéllos casos en los que la empresa inversora hubiera cambiado de objetivo. Precisamente una de las ventajas de estas toeholds radica en que proporcionan a la empresa inversora información de la empresa objetivo a la que difícilmente se puede acceder desde el exterior, lo que les permite valorar en una situación de menor asimetría de información la idoneidad de realizar un mayor compromiso en la empresa objetivo. Nuestros datos apuntarían a que en un porcentaje mayoritario de los casos, las empresas españolas habrían cambiado de idea sobre la adquisición de la empresa local, una vez hubieran accedido a tal información. Estos resultados, no obstante, parecen estar en consonancia con la literatura al respecto. Así, parece existir un gap entre la teoría y la evidencia empírica al respecto, de tal forma que esta última ${ }^{20}$ sugiere que la mayor parte de las empresas que se implican en una primera toma de posición parcial no continúan con un proceso de adquisición posterior -véase, por ejemplo, Choi (1991), Aigbe y otros (2004), Betton y otros (2005)-, de igual forma,

\footnotetext{
${ }^{20}$ Cabe mencionar que la práctica totalidad de estos estudios se refieren a procesos de adquisición realizados por empresas estadounidenses.
} 
la mayor parte de los procesos de adquisición se llevan a cabo sin que haya existido tal posicionamiento previo -en Bris (2002) y Goldman y Qian (2005) se presenta una exhaustiva revisión de la literatura empírica al respecto.

Existe, no obstante, una segunda razón por la que la empresa inversora podría optar por no realizar nuevas inversiones acumulativas: el hecho de que su interés inicial consiste en mantener únicamente tal posición minoritaria en el capital de la empresa participada; hecho que puede obedecer, a su vez, a circunstancias claramente diferenciadas. De un lado, dichas tomas de participación podrían constituir un toehold externo (Lindqvist, 2004a, 2004b), es decir, responder al interés de la empresa inversora de beneficiarse de la externalidad positiva que anticipa se genere ante la realización de procesos de adquisición o fusión (realizados por ella misma o por terceras empresas) en el sector de actividad de la empresa participada. Del otro, tales participaciones minoritarias podrían responder a la participación de la empresa española en una alianza o acuerdo de cooperación de carácter internacional. Así, tal y como se recoge en Vidal y García Canal (2003), la toma de una participación minoritaria en el capital del socio resulta un hecho frecuente en el desarrollo de determinadas alianzas, en particular, aquéllas que surgen de un protocolo de cooperación y presentan, en su origen, un carácter poco definido y no concretado en proyectos ya determinados en el momento de sellar el acuerdo. En este sentido, la participación minoritaria constituiría una prueba de la intención de comportamiento cooperativo por parte de la empresa y de su permanencia en la alianza, erigiéndose en garantía e instrumento que facilita la negociación entre los socios.

En relación con el conjunto adquisiciones integradas en la base inicial y catalogadas como toeholds, hemos intentado identificar un perfil diferenciado de las que han evolucionado en una adquisición posterior, frente a las que no han seguido tal evolución. A tal efecto, no hemos podido identificar diferencias estadísticamente significativas entre ambas muestras en relación con ninguna de las variables relacionadas con el país receptor de la inversión -grado de riesgo país, grado de desarrollo económico, distancia cultural del mismo respecto a España o clasificación del mismo en una determinada área geográfica o económica-, resultando significativa únicamente la pauta sectorial. La Tabla 7 recoge evidencia al respecto, mostrando una significación estadística superior al 95\%. El valor de los residuos ajustados permite constatar que las toeholds realizadas por empresas enmarcadas en el sector financiero presentan una tendencia superior a la observada para el conjunto de la muestra a evolucionar hacia una adquisición posterior. Así, un volumen cercano al $60 \%$ de las toeholds inicialmente identificadas y realizadas por empresas de este sector, experimentaron tal evolución posterior, frente a un escaso $16 \%$ constatado para el resto de los sectores. 
TABLA 7

DISTRIBUCIÓN DE LAS TOEHOLD EN FUNCIÓN DE SU EVOLUCIÓN

\begin{tabular}{|c|c|c|c|}
\hline & Sector financiero & Resto sectores & Total \\
\hline $\begin{array}{c}\text { No evolución adq. } \\
\text { posterior }\end{array}$ & $\begin{array}{c}7 \\
(-2,3)\end{array}$ & $\begin{array}{c}10 \\
(2,3)\end{array}$ & $\mathbf{1 7}$ \\
\hline $\begin{array}{c}\text { Evolución adq. } \\
\text { posterior }\end{array}$ & 10 & 2 & $\mathbf{5 8 , 6}$ \\
\hline Total & $(2,3)$ & $(-2,3)$ & $\mathbf{1 2}$ \\
& $\mathbf{1 7}$ & $\mathbf{1 2}$ & $\mathbf{4 1 , 4 \%}$ \\
\hline
\end{tabular}

Chi Cuadrado $=5,15 * *$ (residuos ajustados entre paréntesis).

Phi: $0,422 * *$ V de Cramer: 0,422** Coeficiente de contingencia: 0,388**.

$* \mathrm{p}<0,1 ; * * \mathrm{p}<0,05 ; * * * \mathrm{p}<0,01$

\section{Conclusiones}

En el presente trabajo se ha analizado la realización de adquisiciones parciales (APs) como fórmula de materializar los procesos de inversión directa en el exterior. A tal efecto, se han identificado, en primer lugar, los rasgos distintivos y propios de este modo de implantación internacional para, a continuación, a partir de la escasa y dispersa literatura al respecto identificar una tipología de adquisiciones parciales atendiendo a diferentes criterios de clasificación.

$\mathrm{Al}$ objeto de analizar, desde un punto de vista empírico, la utilización de esta forma de implantación internacional se ha empleado una muestra de inversiones directas realizadas mediante APs por empresas españolas admitidas a cotización oficial en la Bolsa de Madrid. El período cubierto por nuestro estudio va desde que se produce la definitiva liberalización de la IDE española (1986/1988) hasta el año 2003, siendo las fuentes de datos utilizadas la prensa económica, los comunicados de las empresas a la Comisión Nacional del Mercado de Valores y las memorias anuales presentadas por las empresas. El análisis realizado nos ha permitido obtener el perfil característico de cada uno de los tipos de AP previamente identificados.

Así, en función del porcentaje de capital adquirido y del número de empresas adquirentes hemos identificado cuatro categorías de APs. En primer lugar, las AP Mayoritarias que se caracterizan por localizarse, fundamentalmente, en aquellos países con los que España tiene una mayor distancia cultural y se realizan, principalmente, en los sectores de manufactura y servicios no financieros. Asimismo, estas adquisiciones presentan una tendencia inferior a la media para concurrir a procesos de privatización en el mercado receptor. En segundo lugar, AP Minoritarias que apenas presentan un perfil diferenciado respecto del resto de categorías identificadas. En tercer lugar, las toehold que se localizan, primordialmente, en los países de mayor renta per cápita y distancia cultural respecto a España, con menor riesgo país y, más en concreto, en la UE. Asimismo, presentan una tendencia superior a la media a ser 
la fórmula de adquisición parcial utilizada en el sector financiero. Finalmente, las adquisiciones compartidas se caracterizan porque son la vía de adquisición parcial predominante en mercados con los que España tiene una menor distancia cultural y que presentan un mayor riesgo país y, en particular, se localizan en los países de América Latina. Se utilizan, principalmente, por las empresas de los denominados sectores regulados para concurrir a procesos de privatización en el mercado receptor.

Por lo que respecta a la estabilidad de la participación adquirida, una primera tendencia que se constata en la muestra de inversiones analizadas radica en que la mayor parte de las mismas responden a un perfil de estabilidad en el capital de la empresa participada por parte de la empresa inversora, de tal forma que únicamente un porcentaje minoritario responde a lo que hemos calificado como adquisiciones escalonadas o en etapas. En éstas se produce un cambio gradual en la propiedad de la empresa objetivo que responde al deseo del inversor extranjero de tomar el control de una empresa a partir de una primera posición minoritaria en el capital de la misma, comúnmente denominada toehold. El análisis realizado nos permite constatar que tan solo un volumen muy escaso de estas participaciones minoritarias han sido realizadas con el ánimo de construir tal posición de control posteriormente; antes al contrario, estas tomas de participación por parte de las empresas españolas parecen responder a otros objetivos, como puede ser el constituir el aval o garantía asociado a una alianza o acuerdo de cooperación marco no concretado en el momento de pactar el acuerdo en proyectos conjuntos específicos que deban ser realizado por ambos socios.

Por el contrario, hemos constatado que el perfil de acumulación o inversión posterior en un proyecto ya realizado previamente corresponde con mayor frecuencia a proyectos en los que la primera inversión se materializó a través de lo que hemos calificado como inversiones compartidas o realizadas conjuntamente por varias empresas inversoras, en las que una reordenación posterior de los porcentajes inicialmente tomados por las diferentes empresas implicadas o el abandono de algunas de ellas se traduce en un incremento de la participación por parte de otras.

El presente trabajo constituye un primer paso en el estudio de un modo de implantación internacional apenas abordado por la literatura sobre Gestión Internacional. En el mismo se han identificado tendencias de utilización de los diferentes tipos de APs. Entendemos, en este sentido, que se hacen necesarios nuevos trabajos que profundicen en el estudio de este modo de entrada e identifiquen las pautas que conduzcan a una óptima utilización del mismo.

\section{Referencias}

[1] AIGBE, A.; MADURA, J, y SPENCER, D. (2004). Partial acquisitions, corporate control, and performance. Applied Financial Economics 14, pp. 847-857.

[2] BALAKRISHNAN, S. y KOZA, M. (1993). Information asymmetry, adverse selection and joint ventures. Journal of Economic Behavior and Organization 20, pp. 99-117. 
[3] BARKEMA, H. y VERMEULEN, F. (1998). International expansion through start-up or acquisition: A learning perspective. Academy of Management Journal 41 (1), pp. 7-26.

[4] BEAMISH, P.W. (1988). Multinational Joint Ventures in Developing Countries, Routledge, Londres.

[5] BETTON, S.; THORBURN, K. y ECKBO, B. (2005). The toehold puzzle. Centre for Economic Policy Research Discussion Paper No. 5084.

[6] BLODGETT, L. (1992). Factors in the inestability of international joint ventures: An event history analysis. Strategic Management Journal 13, pp. 475-481.

[7] BRIS, A. (2002). Toehold, takeover premium and the probability of being acquired. Journal of Corporate Finance 8 (3), pp. 227-253.

[8] BROUTHERS, K. y HENNART, J. F. (2007). Boundaries of the firm: Insights from international entry mode research. Journal of Management 33 (3), pp. 395-425.

[9] CAMPA, M. y GUILLÉN, M. (1996). Evolución y determinantes de la inversión directa en el extranjero por empresas españolas. Papeles de Economía Española 66, pp. 235-247.

[10] CHEN, H. y HENNART, J. F. (2004). A hostage theory of joint ventures: Why do Japanese investors choose partial over full acquisitions? Journal of Business Research 57, pp. 1126-1134.

[11] CHOI, D. (1991). Toehold acquisitions, shareholder wealth, and the market for corporate control. Journal of Financial and Quantitative Analysis 26 (3), pp. 391-407.

[12] CHOWDHRY, B. y JEGADEESH, N. (1994). Pre-Tender offer share acquisition strategy in takeovers. Journal of Financial and Quantitative Analysis 29 (1), pp. 117-129.

[13] DELGADO, J.; RAMÍREZ. M. y ESPITIA, M. (1999). Comportamiento inversor de las empresas españolas en el exterior. Informacion Comercial Española 780, pp. 101-112.

[14] DRUG, J. Y HEGARTY, W. (1997). Postacquisition turnover among U.S. top management teams: an analysis of the effects of foreign vs. domestic acquisitions of U.S. targets. Strategic Management Journal 18 (8), pp. 667-675.

[15] DURÁN, J. J. (2006). El auge de la empresa multinacional española. Boletín Económico de ICE 2881, pp. 13-33.

[16] ESTRIN, S. (2002). Competition and corporate governance in transition. Journal of Economic Perspectives 16 (1), pp. 101-124.

[17] GOLDMAN, E. y QIAN J. (2005). Optimal toeholds in takeover contests. Journal of Financial Economics 77 (2), pp. 321-346.

[18] GOMES-CASSERES, B. (1989). The ownership structure of foreign subsidiaries: Theory and evidence. Journal of Economic Behavior and Organizations 11, pp. 1-25.

[19] GROSSMAN, F. y HART, J. (1980). Takeover bids, the free-rider problem, and the theory of the corporation. Bell Journal of Economics 11 (1), pp. 42-64.

[20] GUILLÉN, M. (2004). La internacionalización de las empresas españolas. Información Comercial Española. Revista de Economía 812, pp. 211-224.

[21] GUILLÉN, M. y TSCHOEGL, A. (2002). The internalization of retail banking: the case of Spanish banks in Latin America. Transnational Corporations 9 (3), pp. 63-97.

[22] HENISZ, W. (2003). The power of the Buckley and Casson thesis: The ability to manage institutional idiosyncrasies. Journal of International Business Studies 34 (2), pp. 173-84.

[23] , J. F. (1988). A transaction cost theory of equity joint ventures. Strategic Management Journal 9, pp. 361-374.

[24] HENNART, J. F. y REDDY, S. (1997). The choice between mergers/acquisitions and joint ventures: The case of Japanese investors in the United States. Strategic Management Journal 18, pp. 1-12. 
[25] HENNART, J. F. y REDDY, S. (2000). Digestibility and asymmetric information in the choice between acquisitions and joint ventures: Where's the beef? Strategic Management Journal 21 (2), pp. 191-194.

[26] HIRSHLEIFER, D. y TITMAN, S. (1990). Share tendering strategies and the success of hostile takeover bids. Journal of Political Economy 98, pp. 295-324.

[27] HOUSE, R.; HANGES, P.; JAVIDAN, M.; DORFMAN, P. y GUPTA, V. (2004). Culture, leadership, and organizations. The GLOBE Study of 62 Societies, Sage Publications, California.

[28] JAKOBSEN, K. y MEYER, K. (2007). Partial acquisitions: The overlooked entry mode en J. H. Dunning y P. Gugler (eds.), Recent Advances in International Business Research, Elsevier Science, pp. 203-226.

[29] KILLING, J. P. (1983). Strategies for Joint Venture Success, Praeger, Nueva York.

[30] KOBRIN, S. J. (1987). Testing the bargaining hypothesis in the manufacturing sector in developing countries. International Organization, Autumn, pp. 609-638.

[31] KOGUT, B. (1991). Joint ventures and the option to expand and acquire. Management Science 37, pp. 19-33.

[32] KOGUT, B. y KULATILAKA, N. (1994). Options thinking and platform investments: Investing in opportunity. California Management Review 36 (2), pp. 52-71.

[33] KOGUT, B. y SINGH, H. (1988). The effect of national culture on the choice of entry mode. Journal of International Business Studies 19, pp. 411-432.

[34] LECRAW, D. (1984). Bargaining power, ownership, and profitability of transnational corporations in developing countries. Journal of International Business Studies, Spring/ Summer, pp. 27-43.

[35] LINDQVIST, T. (2004a). Acquisitions strategies: empirical evidence of outsider toeholds. Working paper 634, The Research Institute of Industrial Economics, Suecia.

[36] LINDQVIST, T. (2004b). Mergers by partial acquisitions. Working paper 630, The Research Institute of Industrial Economics, Suecia.

[37] LÓPEZ-DUARTE, C. y GARCÍA-CANAL, E. (2002). Adverse selection and the choice between joint-ventures and acquisitions: Evidence from Spanish firms. Journal of Institutional and Theoretical Economics (JITE) 158 (2), pp. 304-324.

[38] MADHOK, A. (1997). Cost, value and foreign market entry mode: The transaction and the firm. Strategic Management Journal 18, pp. 39-61.

[39] MEYER, K. E. (2002). Management challenges in privatization acquisitions in transition economies. Journal of World Business 37 (4), pp. 266-276.

[40] MEYER, K. E. y TRAN, F. (2006). Market penetration and acquisition strategies for emerging economies. Long Range Planning 39, pp. 177-197.

[41] MEYER, K. E. y ESTRIN, S. (eds.) (2006). Acquisition strategies in emerging markets, Palgrave-McMillan.

[42] OECD (1993). Recent developments in foreign direct investment: A sectorial analysis. Financial Market Trends, febrero, pp. 67-86.

[43] RAMÍREZ. M.; DELGADO, J. y ESPITIA, M. (2004). Destino de las inversiones españolas: países industriales versus países en desarrollo. Revista de Economía Aplicada 34 (12), 127-140.

[44] RAVID, A. y SPIEGEL, M (1999). Toehold strategies, takeover law and rival bidders. Journal of Banking and Finance 12, pp. 1219-1242.

[45] Real Decreto 664/1999, de 23 de abril, sobre inversiones exteriores. 
[46] Real Decretos 672/1992, de 2 de julio, sobre inversiones españolas en el exterior.

[47] REUER, J. y KOZA, P. (2000). On lemons and indigestibility: Resource assembly through joint ventures. Strategic Management Journal 21 (2), pp. 195-197.

[48] RUIZ-MORENO, F.; MAS-RUIZ, F. y NICOLAU, J. (2007). Two-stage choice process of FDI: Ownership structure and diversification mode. Journal of Business Research 60, pp. 795-805.

[49] SHLEIFER, A. y VISHNY, R. (1986). Large shareholders and corporate control. Journal of Political Economy 94 (3), pp. 461-488.

[50] SPENCER, C, AKHIGBE, A. y MADURA, J. (1998). Impact of partial control on policies enacted by partial targets. Journal of Banking and Finance 22 (4), pp. 425-445.

[51] SUDARSANAM, S. (1995). The essence of mergers and acquisitions, Prentice Hall.

[52] VIDAL, M. y GARCÍA CANAL, E. (2003). Discrecionalidad directiva y creación de valor en la formación de alianzas globales para la internacionalización. Cuadernos de Economía y Dirección de la Empresa 16, pp. 85-104.

[53] WOODCOCK, C.; BEAMISH, P. y MAKINO, S. (1994). Ownership-based entry mode strategies and international performance. Journal of International Business Studies, $2 .^{\circ}$ quatrimestre, pp. 253-273. 